\title{
Distúrbios intracapsulares da articulação temporomandibular: da semiologia à terapêutica: uma revisão de literatura
}

\author{
Intracapsular disorders of temporomandibular joint: from semiology to therapeutic: a literature \\ review
}

Transtornos intracapsulares de la articulación temporomandibular: de la semiologia a la terapia: revisión de la literatura

\author{
Geovanna Caroline Brito da Silva \\ ORCID: https://orcid.org/0000-0002-8943-5638 \\ Universidade Estadual da Paraíba, Brasil \\ E-mail: geovannacarolineb@gmail.com \\ Edjardi de Pontes Viana \\ ORCID: https://orcid.org/0000-0002-3506-8684 \\ Universidade Estadual da Paraíba, Brasil \\ E-mail: edjardipontes@gmail.com \\ Francielly de Lemos Medeiros \\ ORCID: https://orcid.org/0000-0002-8672-7731 \\ Universidade Estadual da Paraíba, Brasil \\ E-mail: franciellylemos12@gmail.com \\ Layla Narrely Santos Alves \\ ORCID: https://orcid.org/0000-0002-7497-3361 \\ Universidade Estadual da Paraíba, Brasil \\ E-mail: narrelylayla@gmail.com \\ Marcelo Gadelha Vasconcelos \\ ORCID: https://orcid.org/0000-0003-0396-553X \\ Universidade Estadual da Paraíba, Brasil \\ E-mail: marcelo.vasconcelos@yahoo.com.br \\ Rodrigo Gadelha Vasconcelos \\ ORCID: https://orcid.org/0000-0002-7890-8866 \\ Universidade Estadual da Paraíba, Brasil \\ E-mail: rodrigogadelhavasconcelos@yahoo.com.br
}

\begin{abstract}
Resumo
Introdução: As disfunções temporomandibulares (DTM's) são condições capazes de afetar diretamente a anatomia e as características funcionais da articulação temporomandibular (ATM). Elas podem ser classificadas conforme as estruturas afetadas em: Disfunção Muscular ou DTM extracapsular, quando envolve componentes do sistema mastigatório como os músculos e Disfunção Articular ou DTM intracapsular, quando afeta diretamente a ATM. Objetivo: Este trabalho consiste em uma revisão da literatura que objetiva descrever fatores etiológicos, sintomatologia, sinais clínicos, métodos de diagnóstico e modalidades de tratamento existentes dos distúrbios intracapsulares da ATM. Metodologia: Realizou-se uma busca nas bases de dados eletrônicas: PubMed, SciELO e Google Acadêmico, através do rastreio de artigos publicados entre 2005 e 2020, além de livros considerados proveitosos para o conteúdo deste estudo. Resultados: Os distúrbios intracapsulares da ATM estão associados a uma etiologia multifatorial, podendo apresentar sintomas e sinais clínicos semelhantes entre si, à exemplo, dor orofacial de intensidade variável, limitação dos movimentos mandibulares e ruídos articulares. Os exames de imagem são decisivos para o diagnóstico clínico dos distúrbios. Em relação aos tratamentos, os conservadores são preconizados e caso não mostrem eficácia, técnicas cirúrgicas são preconizadas. Conclusão: o papel do cirurgião-dentista no atendimento primário do paciente com DTM é imprescindível para um melhor prognóstico terapêutico, refletindo, sobretudo, na redução das cronificações da doença, visto que o diagnóstico precoce e o início de um tratamento que induza a adaptação da articulação frente às desordens podem impedir a evolução para quadros clínicos mais severos, como doenças degenerativas.
\end{abstract}

Palavras-chave: Distúrbios intracapsulares; Articulação temporomandibular; Disfunções temporomandibulares.

\section{Abstract}

Introduction: Temporomandibular disorders (TMD's) are conditions capable of directly affecting the anatomy and functional characteristics of the temporomandibular joint (TMJ). They can be classified according to the structures 
affected in: Muscular Dysfunction or extracapsular TMD, when it involves components of the masticatory system such as the muscles and Joint Dysfunction or intracapsular TMD, when it directly affects the TMJ. Objective: This work consists of a literature review that aims to describe etiological factors, symptoms, clinical signs, diagnostic methods and existing treatment modalities for TMJ intracapsular disorders. Methodology: A search was conducted in the electronic databases: PubMed, SciELO and Google Scholar, through the tracking of articles published between 2005 and 2020, in addition to books considered useful for the content of this study. Results: Intracapsular TMJ disorders are associated with a multifactorial etiology and may present symptoms and clinical signs similar to each other, for example, orofacial pain of varying intensity, limited jaw movements and joint noise. Imaging exams are decisive for the clinical diagnosis of disorders. Regarding treatments, conservatives are recommended and, if they do not show efficacy, surgical techniques are recommended. Conclusion: the role of the dentist in the primary care of patients with TMD is essential for a better therapeutic prognosis, reflecting, above all, in reducing the chronicity of the disease, since the early diagnosis and the beginning of a treatment that induces the adaptation of the disease. articulation in the face of disorders can prevent progression to more severe clinical conditions, such as degenerative diseases.

Keywords: Intracapsular disorders; Temporomandibular joint; Temporomandibular disorders.

\begin{abstract}
Resumen
Introducción: Los trastornos temporomandibulares (TMD) son afecciones capaces de afectar directamente la anatomía y las características funcionales de la articulación temporomandibular (TMJ). Se pueden clasificar según las estructuras afectadas en: Disfunción Muscular o DTM extracapsular, cuando involucra componentes del sistema masticatorio como los músculos y Disfunción Articular o DTM intracapsular, cuando afecta directamente a la ATM. Objetivo: Este trabajo consiste en una revisión de la literatura que tiene como objetivo describir factores etiológicos, síntomas, signos clínicos, métodos de diagnóstico y modalidades de tratamiento existentes de los trastornos intracapsulares de la ATM. Metodología: Se realizó una búsqueda en las bases de datos electrónicas: PubMed, SciELO y Google Scholar, mediante el seguimiento de artículos publicados entre 2005 y 2020, además de libros considerados útiles para el contenido de este estudio. Resultados: Los trastornos de la ATM intracapsular se asocian con una etiología multifactorial y pueden presentar síntomas y signos clínicos similares entre sí, por ejemplo, dolor orofacial de intensidad variable, movimientos mandibulares limitados y ruido articular. Los exámenes de imagen son decisivos para el diagnóstico clínico de trastornos. En cuanto a los tratamientos, se recomiendan los conservadores y, si no muestran eficacia, se recomiendan las técnicas quirúrgicas. Conclusión: el papel del odontólogo en la atención primaria de pacientes con TTM es fundamental para un mejor pronóstico terapéutico, reflejándose, sobre todo, en la reducción de la cronicidad de la enfermedad, desde el diagnóstico precoz y el inicio de un tratamiento que induce la adaptación de la enfermedad La articulación frente a trastornos puede prevenir la progresión a condiciones clínicas más graves, como enfermedades degenerativas.
\end{abstract}

Palabras clave: Trastornos intracapsulares; Articulación oreja-mandíbula; Trastornos temporomandibulares.

\title{
1. Introdução
}

A articulação temporomandibular (ATM) é formada por meio da incorporação do processo condilar da mandíbula na fossa glenóide do osso temporal e possui sua movimentação, sobretudo, através da dinâmica dos músculos mastigatórios (Gauer \& Semidey, 2015). Constantemente, a dor craniofacial associada à ATM, bem como a musculatura da mastigação e inervações musculares da cabeça e pescoço configura-se como um dos principais sintomas das disfunções temporomandibulares (DTM's) (Scrivani et al., 2008; Sobral et al., 2020).

Nesse contexto, o termo disfunção temporomandibular (DTM) é coletivo para representar um grupo de condições osteomusculares heterogêneas que acomete a região orofacial (Jordani et al., 2019; Galvão et al., 2020), afetando diretamente a anatomia e as características funcionais da ATM (Gil-Martínez et al., 2018). Por conseguinte, as DTM's podem ser subdivididas em distúrbios articulares e não-articulares, também denominados de condições intracapsulares e extracapsulares, respectivamente (Liu \& Steinkeler, 2013; Dalewski et al., 2019). Os distúrbios que acometem elementos internos da articulação são categorizados como intracapsulares e as desordens que afetam as estruturas circundantes da ATM, por sua vez, são compreendidas como extracapsulares (Okeson, 2008) e a maior parte delas engloba condições crônicas, como fibromialgia, tensão muscular e miopatias (Scrivani et al., 2008).

A etiologia da DTM é complexa, visto que é vinculada à múltiplos fatores (SOUSA et al., 2020), sendo eles: biológicos, sociais, ambientais, emocionais e cognitivos (Scrivani et al., 2008). Dessa forma, a identificação e controle dos 
fatores etiológicos são cruciais para garantir o êxito do tratamento. Inicialmente, é recomendado uma conduta conservadora e não invasiva: terapia com placa oclusal, farmacoterapia e fisioterapia (SobraL et al., 2020). No entanto, apesar de existirem, atualmente, amplas modalidades de tratamento, destacam-se o aconselhamento educacional e autocuidado (orientação do profissional ao paciente para tentar minimizar o agravamento do quadro da doença, como indicar uma dieta leve, repouso da mandíbula, evitar estresse/ansiedade), laserterapia, acupuntura, neurofeedback e a cirurgia (Galvão et al., 2020), devido a etiologia da DTM ser de caráter multifatorial, torna-se mais difícil a realização do diagnóstico e tratamento (Lima et al., 2020).

Dessa forma, embora seja clara a importância que as DTM'S têm sobre o funcionamento de todo o aparelho estomatognático e de suas consequentes implicações na qualidade de vida dos indivíduos, percebe-se ainda a escassa atenção atribuída a esse tema no cotidiano das unidades de saúde. À vista disso, levando em consideração que se trata de uma alteração de ordem multifatorial, deveria ser objeto de maior observação por todos os profissionais, contemplando, dessa forma, o cuidado integral do paciente, um dos atributos da Atenção Primária em Saúde (Lima et al., 2020).

Diante do contexto apresentado e tendo em vista que as DTM's são condições, atualmente, muito comuns na população e apesar disso, sua discussão ainda ser complexa na literatura, a realização deste estudo fundamenta-se na necessidade de um conhecimento mais aprofundado acerca dos distúrbios articulares (intracapsulares), de forma a contribuir com estudos nesta área, buscando uma maior elucidação sobre o tema. Nesse sentido, o objetivo desta revisão de literatura fundamenta-se numa compilação de informações que permita desde a descrição de fatores etiológicos, sintomatologia, características clínicas, métodos de diagnóstico até modalidades de tratamento existentes dos distúrbios intracapsulares que podem acometer a ATM, com o propósito de melhorar a compreensão dos cirurgiões-dentistas sobre os aspectos gerais de cada condição, facilitando assim, a sua deteção e, eventualmente, o processo de decisão clínica diante de algum atendimento de um paciente acometido por tais distúrbios.

\section{Metodologia}

O presente estudo constitui uma revisão literária do tipo narrativa realizada através de um levantamento bibliográfico de artigos científicos originais publicados no período entre 2005 e 2020. Para isso, foram utilizadas as seguintes bases de dados eletrônicos nacionais e internacionais: PubMed - U.S. National Library of Medicine, SciELO (Scientific Electronic Library) e o Scholar Google (Google Acadêmico). Além dos artigos levantados nas referidas bases de dados, também foram consultados cinco livros que apresentam informações de ênfase ao tema dessa revisão.

Para a filtragem e seleção das publicações, foram utilizadas as palavras-chaves: distúrbios intracapsulares da ATM (intracapsular TMJ disorders), desarranjos internos da ATM (internal derangements of TMJ) e disfunção da ATM (TMJ dysfunction). Adicionalmente, a busca manual nas listas de referências dos artigos selecionados foi um recurso utilizado.

A pesquisa ocorreu em três fases:

1. Busca nas bases de dados com os descritores selecionados;

2. Leitura dos títulos e resumos com a finalidade de obter um entendimento prévio acerca do assunto principal abordado e definição dos artigos a serem incluídos;

3. Leitura dos artigos na íntegra e construção dos resultados.

Como critérios de inclusão foram considerados: artigos escritos em inglês, espanhol e português, aqueles cujo conteúdo se enquadrava no enfoque e objetivo do trabalho, bem como os mais pertinentes no que se refere à abrangência das informações desejadas. Também foram analisados aspectos de disponibilidade integral do texto do estudo e clareza no 
detalhamento metodológico utilizado. Por outro lado, foram excluídos da amostra trabalhos que não exibiram relevância sobre o tema abordado e que não se enquadraram nos critérios de inclusão.

\section{Revisão de Literatura}

\subsection{Anatomofisiologia da articulação temporomandibular (ATM)}

Em comparação com as outras articulações diartrodiais, a ATM, possui determinada suscetibilidade à injúrias perinatais e pós-natais, em virtude de ser pouco desenvolvida ao nascimento, visto que seu surgimento na região craniofacial não ocorre até a oitava semana de gravidez. Assim, o desenvolvimento dessa articulação ocorre continuadamente nos primeiros anos da infância à medida que a mandíbula é utilizada para realização dos movimentos de sucção e, eventualmente, mastigação (Bag et al., 2014).

A ATM é uma das articulações mais complexas do corpo humano (Aires et al., 2020; Lima et al., 2020), sendo composta pelo côndilo mandibular articulado a nível de fossa glenóide, na base do crânio, com a interposição de um disco cartilaginoso entre as superfícies articulares. Embriologicamente, a ATM desenvolve-se a partir de uma cartilagem hialina, constituindo um importante centro de crescimento da face (Hamza et al., 2020; Lima et al., 2020). A cápsula articular e ligamentos também compõem essa articulação (Vilar et al., 2020).

O disco ou menisco articular possui um formato bicôncavo e está posicionado entre ambas as superfícies articulares (Neto et al., 2013). Essa estrutura é composta por um tecido conjuntivo fibroso denso e se subdivide em três segmentos: a porção anterior, uma fina zona intermediária e a porção posterior (Shaffer et al., 2014). Em uma articulação normal, a zona intermediária do disco encontra-se sempre, nas posições de boca aberta e fechada, interposta entre o côndilo e o osso temporal com o intuito de prevenir danos articulares (Bag et al., 2014). Nesse âmbito, dois movimentos acontecem na ATM durante a abertura mandibular. Primeiramente, ocorre a rotação em torno de um eixo horizontal através das cabeças condilares e, posteriormente, ocorre a translação anterior do disco para uma posição abaixo da eminência articular (Aiken et al., 2012).

Por outro lado, a cápsula fibrosa é um delgado tecido que circunda integralmente a articulação (Alomar et al., 2007), envolvendo a fossa mandibular e a eminência articular superiormente, colo e cabeça da mandíbula inferiormente, onde, desse modo ocorre o selamento hermético da ATM (Vilar et al., 2020). Essa estrutura é envolvida por um fluido lubrificante, denominado de líquido sinovial (Stocum \& Roberts, 2018).

Por sua vez, a membrana sinovial é outro componente que se apresenta como um tecido conjuntivo vascularizado, formado por vasos capilares, linfáticos e escassas fibras nervosas, tendo como função o revestimento da cápsula articular a fim de delimitar a sinóvia, sendo este, um fluido sinovial viscoso, rico em prostaglandinas. Este líquido é secretado pelas células da camada sinovial com intuito de lubrificação, proteção e nutrição da ATM (Vilar et al., 2020).

A estabilidade do disco acima do côndilo durante o amplo movimento da articulação é possibilitada pela existência de um tecido retrodiscal de suporte, composto de gordura, feixes vásculonervosos e uma zona bilaminar fibrocartilaginosa, com bandas ou ligamentos superior e inferior, que se fixam à cápsula articular e ao osso temporal (Abbehusen, 2019). Dessa forma, os ligamentos são essenciais para a manutenção da integridade e limitação da articulação. Eles são formados por fibras colágenas e possuem comprimentos específicos, como também baixa capacidade de distensão, quando isso ocorre, geralmente os ligamentos se alongam. Esse alongamento, por sua vez, provoca mudanças na biomecânica das ATM's, o que pode acarretar algumas alterações articulares (Okeson, 2007).

Nesse contexto, o entendimento do crescimento e da biomecânica da ATM é fundamental para uma avaliação radiográfica precisa (Tamimi et al., 2018). Além disso, entender a função normal dessa estrutura também é relevante para que 
os profissionais consigam diagnosticar de maneira efetiva possíveis disfunções da articulação, visto que o principal propósito do tratamento é o reestabelecimento do seu funcionamento normal (Okeson, 2007).

Portanto, o conhecimento acerca da anatomofisiologia do complexo temporomandibular e anexos, das sintomatologias e da sua correlação com os distúrbios associados à DTM, somado ao reconhecimento do prognóstico e do manejo de pacientes acometidos, permite ao cirurgião-dentista o diagnóstico precoce, o que pode impedir o desenvolvimento de doenças sintomáticas crônicas (de Brito Silva et al., 2020).

\subsection{Classificação dos distúrbios temporomandibulares}

Conforme a American Academy of Orofacial Pain, as DTM's são classificadas em dois grupos: as DTM miogênicas, que são mais associadas aos distúrbios da musculatura mastigatória e a DTM artrógena, que está mais relacionada à própria articulação temporomandibular (Calis et al., 2019).

Nessa perspectiva, os sinais e sintomas da ATM podem ser agrupados de acordo com as estruturas afetadas em: Disfunção Muscular ou DTM extracapsular, quando estão envolvidos componentes do sistema mastigatório como os músculos e Disfunção Articular ou DTM intracapsular, quando afeta diretamente a ATM (Lima et al., 2020; Liu \& Steinkeler, 2013).

\subsection{Distúrbios intracapsulares da ATM: considerações gerais}

As desordens articulares da ATM propriamente ditas, caracterizam-se por sinais clínicos evidentes de disfunção do sistema estomatognático. Os sons articulares são um dos sinais mais frequentes e quando presentes, são indicativos de um conjunto de três amplas categorias: desarranjos do complexo disco-côndilo; incompatibilidade estrutural das superfícies articulares e alterações inflamatórias da ATM. Embora se tenha uma semelhança clínica expressiva, o tratamento das diversas apresentações é distinto, sendo importante diferenciá-las clinicamente (Scrivani et al., 2008).

Assim, previamente a qualquer tipo de tratamento de uma desordem intracapsular da ATM, alguns fatores necessitam de análise durante o diagnóstico, incluindo: o alinhamento do disco, a causa do desarranjo, a condição do disco e das estruturas ósseas, o nível de desconforto e disfunção, o potencial para futuras patologias e suas consequências e de mudanças adaptativas para a correção do problema (Dawson, 2008). Adiante serão discutidos, com maior foco, os distúrbios intracapsulares da ATM e seguindo o objetivo desse estudo, será abordada a etiologia, sintomatologia, sinais clínicos, diagnóstico e tratamento de cada condição com base em informações presentes em estudos da literatura.

\subsection{Desvios na forma}

\subsubsection{Alterações na superfície articular}

As superfícies articulares da ATM consistem de um periósteo modificado que produz fibrocartilagem quando exposto a grande intensidade de cargas (Roberts \& Goodacre, 2020). Essas estruturas articulares são compostas pelo osso temporal, a fossa mandibular, o tubérculo articular e o côndilo mandibular (Bavaresco et al., 2020). Nesse contexto, os desvios de forma são caracterizados por situações em que as superfícies irregulares do côndilo ou da fossa acabam formando obstáculos mecânicos para o disco (Paiva, 2008). Logo, determinados distúrbios de interferência do disco são devido as alterações entre as superfícies articulares (Okeson \& Leeuw, 2011).

A maioria dos defeitos nessas estruturas que demandam tratamento, estão localizados na superfície condilar e podem ter associação com outras condições, entre elas: distúrbios hormonais, artrite reumatoide, artrose e degeneração condilar idiopática, o que pode provocar modificações dos movimentos mandibulares e queixas álgicas constantes (Neto et al., 2013). 
Dentre os fatores etiológicos que podem promover essas irregularidades na superfície articular pode-se citar: trauma à mandíbula quando os dentes manifestam mal oclusão, inflamação, desequilíbrios estruturais ou condições de desenvolvimento, tais como remodelamento fisiológico relacionado a forças adversas. Ademais, é possível que exista dada conexão com outros distúrbios, como a anquilose fibrosa (Neto et al., 2013).

A Figura 1 exposta a seguir traz três imagens. Na imagem A observamos uma tomografia computadorizada da ATM direita e esquerda de uma paciente pediátrico com histórico de trauma frontal na região do mento. Notamos que a cabeça do côndilo se apresenta irregular (apontada pela seta) e a fossa mandibular apresenta alteração de forma. Essas estruturas da ATM fisiologicamente deveriam serem lisas e deslizantes. Na imagem B nota-se um paciente com severa limitação de aberture devido à defeitos na superfície articular. Já na imagem $\mathrm{C}$ observamos a vista extroral frontal do paciente tentando sua abertura máxima (Neto et al., 2013).

Figura 1 - (A) Tomografia computadorizada da ATM direita (R) e esquerda de paciente pediátrico com histórico de trauma frontal na região do mento. a) Cabeça do côndilo. b) Fossa mandibular. (B) Paciente com severa limitação de abertura devido à defeitos na superfície articular. (C) Vista extraoral frontal do paciente tentando sua abertura máxima.

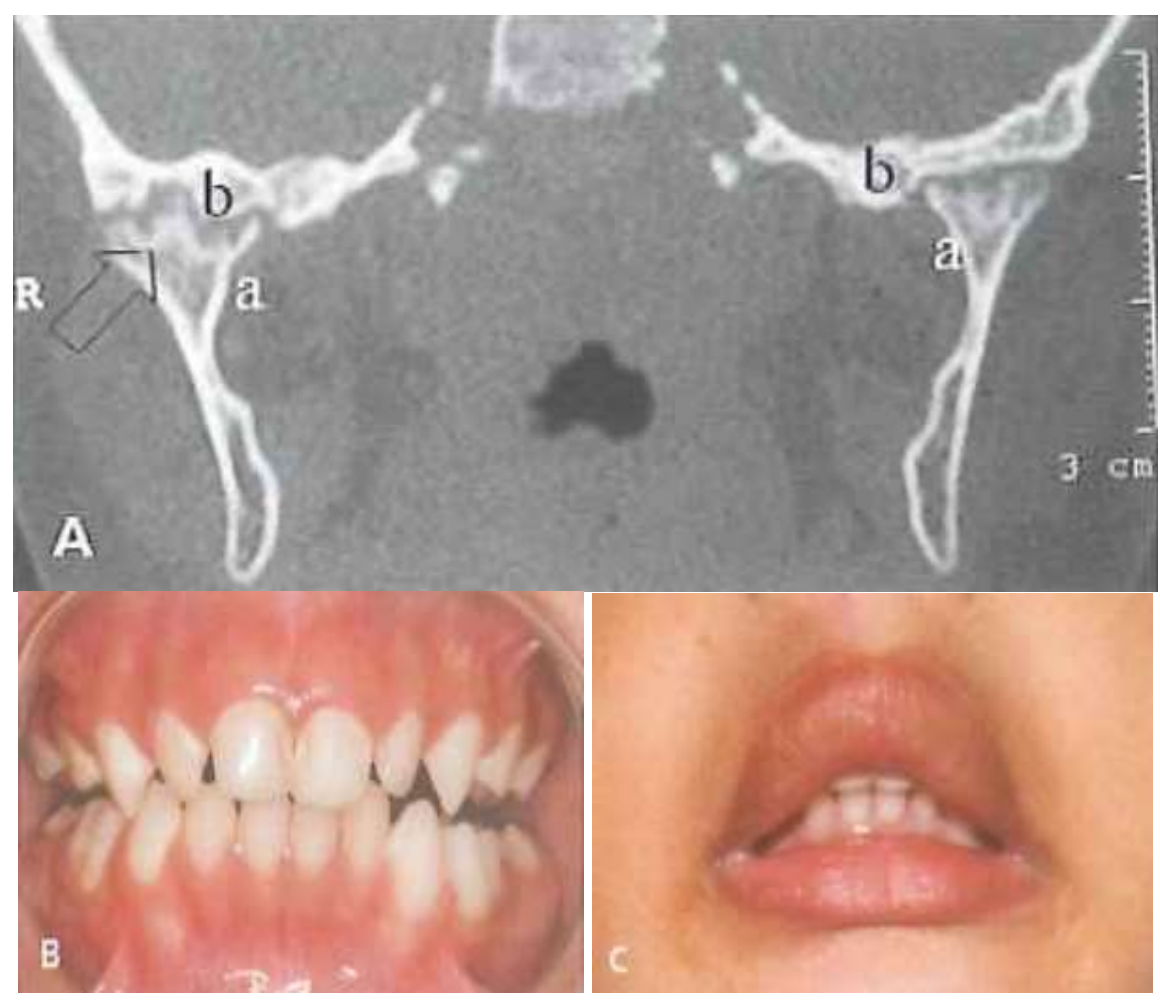

Fonte: Imagens retiradas do livro Oclusão, cap. 6, p. 81. (Neto et al., 2013).

Um dos sinais clínicos característicos causados pela alteração dessas superfícies é o comprometimento do movimento mandibular que pode ser observado na forma de desvio em abertura (Neto et al., 2013). Além disso, a dor representa um dos sintomas predominantes que se manifestam em decorrência de problemas funcionais da ATM e é derivada, justamente, de estruturas articulares saudáveis que são exploradas mecanicamente durante sua função (Okeson \& Leeuw, 2011).

Uma articulação saudável apresenta uma boa lubrificação pelos líquidos sinoviais, suas superfícies fibrocartilaginosas encontram-se ilesas e durante seu funcionamento são silenciosas. Portanto, durante a manobra de auscultação das ATM's não se evidencia nenhuma crepitação (Dawson, 2008). Sendo assim, um dos métodos de diagnóstico importantes para distinguir defeitos de forma e deslocamentos de disco é o som emitido das deformações morfológicas que ocorrem, constantemente, na 
mesma posição, na abertura e no fechamento, em contrapartida, os ruídos de redução acontecem em posições diferentes (Paiva, 2008).

Sob outra perspectiva, o teste de manipulação durante a realização do exame físico também é uma etapa relevante para o processo de diagnóstico, visto que através dele é possível detectar sinais de tensão ou sensibilidade das articulações, bem como indícios de restrição e desconforto durante a realização de movimentos de rotação, protusão e lateralidade da mandíbula (Paiva, 2008).

Dessa forma, durante a avaliação da ATM, é importante que o examinador tenha habilidade nos movimentos mandibulares, em condições normais. A normalidade de todos os movimentos consiste em: suavidade, ausência de barulho, dor, desvios e deflexões. Ademais, as medições também são relevantes, sendo elas: abertura máxima, protrusão e lateralidade (Vilar et al., 2020).

Exames de tomografia computadorizada de feixe cônico e radiografias panorâmicas, por outro lado, são muito úteis, visto que fornecem imagens detalhadas das estruturas ósseas da articulação. Portanto, os cirurgiões-dentistas devem associar os sinais e sintomas apresentados e as imagens da ATM para traçar o diagnóstico e intervenções terapêuticas (De Rossi et al., 2014).

No que se refere ao tratamento, o paciente afetado por defeito da superfície articular deve ser motivado a desenvolver um trajeto de movimento mandibular que impeça a interferência com a finalidade de que ocorra uma adaptação na área comprometida. Além disso, deve ser feito um empenho para suprimir hábitos abusivos, bem como para diminuir a força mastigatória, como mastigar do lado comprometido; podendo esta ser uma alternativa conveniente, uma vez que reduz a pressão intra-articular (Neto et al., 2013).

\subsubsection{Afinamento e perfuração do disco}

O excesso de carga na ATM durante o apertamento dentário pode gerar um afinamento na porção central do disco. A constante pressão exercida, presumivelmente, pode levar à perfuração do corpo médio do disco, originando um orifício arredondado com extremidades fragmentadas. Essa alteração estrutural, por sua vez, em virtude de ser resultante de anos de desgaste, acomete, de maneira mais frequente, pessoas idosas e possui determinada capacidade de induzir mudanças degenerativas nas superfícies articulares (Neto et al., 2013).

A perfuração do disco da ATM pode ser dividida em: central (quando se localiza na área do próprio disco) e periférica (que ocorre na zona de transição, no ponto de inserção do tecido restrodiscal no disco) (Machoñ et al., 2020). Prevalentemente, essa condição acomete mais mulheres (Li et al., 2019; Liu et al., 2010) e a sua taxa de incidência progride de acordo com o aumento da idade (Liu et al., 2010), em decorrência disso, tal distúrbio é muito observado em pacientes com osteoartrite secundária (Kim et al., 2018) causada por desarranjo interno, lesão e infecção (Xu et al., 2012).

A relação anormal do disco intra-articular com o côndilo e o osso temporal representa uma das causas mais comuns de perfuração de disco (Liu et al., 2010). Em um estudo retrospectivo com 33 pacientes acometidos por perfuração de disco, Machon et al. (2017) evidenciaram que os fatores etiológicos mais frequentes foram estresse e atividades parafuncionais relacionadas. Outras condições, como doenças da coluna cervical e músculos do pescoço, assim como trauma mandibular podem estar associadas à etiologia, visto que são encontrados de maneira frequente em indivíduos que manifestam essa deformação discal (Machon et al., 2017).

Em alguns casos, pacientes que apresentam disco perfurado podem ser assintomáticos. Contudo, quando ocorre o contrário, clinicamente é possível evidenciar manifestações que englobam ruídos, restrição do movimento mandibular e dor (Machon et al., 2017). Múltiplos cliques durante abertura bucal indicam perfuração do disco ou alterações na forma da articulação (Vilar et al., 2020). Desse modo, a crepitação está comumente ligada à irregularidade das superfícies articulares em 
virtude da remodelação ou osteoartrite, correspondendo assim, a um importante sinal indicativo de perfuração de disco ou dos tecidos retrodiscais (Okeson \& Leeuw, 2011). Outro sinal clínico que pode ser encontrado devido ao rompimento discal é a alteração oclusal no momento em que os dentes estão em máxima intercuspidação, visto que a oclusão se modifica conforme a presença ou ausência de fragmentos de disco entre as superfícies articulares (Neto et al., 2013).

A ressonância magnética e a artroscopia diagnóstica têm sido utilizadas para diagnosticar essa disfunção, todavia a artroscopia proporciona informações mais detalhadas (Machon et al., 2017; Kim et al., 2018), dado que fornece uma satisfatória visualização da articulação e, apesar de ser uma técnica invasiva que pode causar dor e desconforto ao paciente já que, em algumas situações, é difícil acessar o local perfurado, tem como principal vantagem a boa precisão a respeito da localização, tipo e extensão da perfuração (Muñoz-Guerra et al., 2013; Kim et al., 2018).

Na Figura 2 apresentada logo abaixo, a imagem A consiste numa ressonância magnética em posição de boca fechada de perfuração de disco da ATM de uma mulher de 52 anos, que está sendo mostrada pela seta. A superfície do côndilo era irregular e o osteófito se formou, projetando para a cavidade sem conexão com o osso cortical da fossa glenóide em uma sequência T1 de ressonância magnética convencional. Já na imagem B foi detectada uma perfuração do disco, indicada pela seta, durante a cirurgia artroscópica (Shen et al., 2014).

Figura 2 - (A) Ressonância magnética em posição de boca fechada de perfuração de disco da ATM de uma mulher de 52 anos (seta). (B) A perfuração do disco foi detectada durante a cirurgia artroscópica (seta).
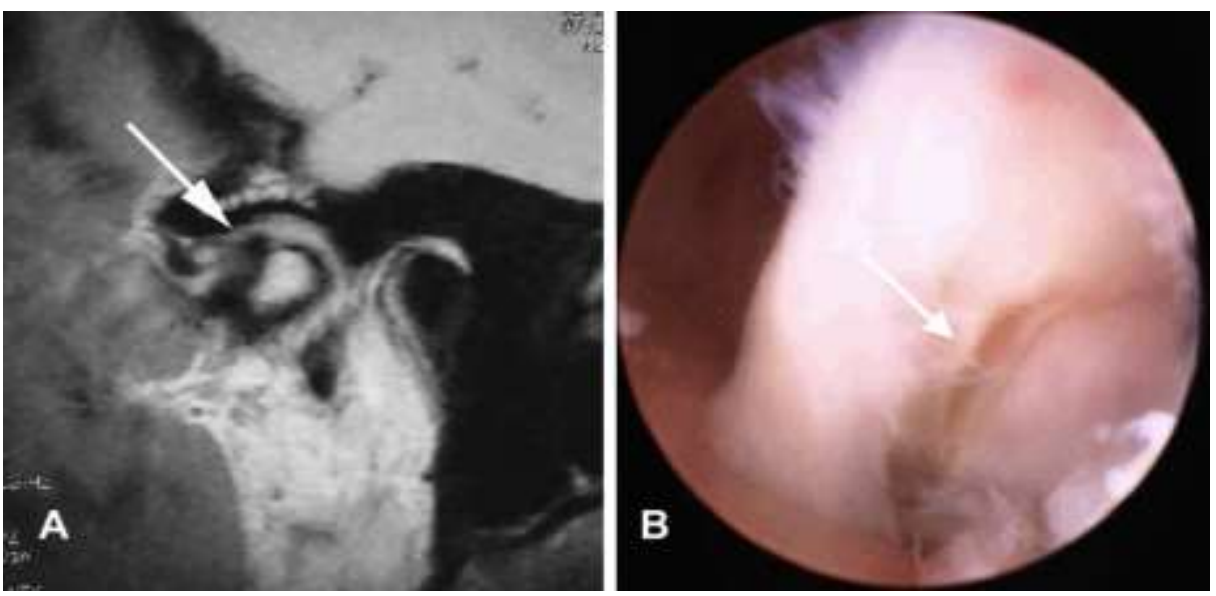

Fonte: (Shen et al., 2014).

Geralmente, as perfurações no disco não possuem capacidade de reparação porque a cartilagem dessa estrutura não é provida de vasos sanguíneos (Xu et al., 2012). Desse modo, para o tratamento desse distúrbio pode ser feita a lavagem artroscópica da articulação, lise de aderências, raspagem da margem de perfuração, sutura ou fixação do disco ou cauterização retrodiscal, caso haja necessidade (Muñoz-Guerra et al., 2013).

Quando a terapia mini-invasiva e a artroscopia não apresentam efeito, uma possibilidade de tratamento para a perfuração é a discectomia com substituição do disco, em que materiais alogênicos ou autólogos são usados para substituir o disco (Machoñ et al., 2020). Nessa perspectiva, folhas de silicone, enxerto dérmico autógeno, enxerto derme-gordura, enxerto de cartilagem auricular, retalho de fáscia temporoparietal, retalho miofascial temporal e retalho de gordura livre são os materiais utilizados (alogênicos ou autólogos) para substituição discal (Demerle et al., 2017; DimitrouliS, 2011).

Miloro e Henriksen (2010) após a realização de 32 discectomias em 24 pacientes, com acompanhamento de aproximadamente 40 meses, constataram que todos eles alcançaram uma melhora na função dos movimentos mandibulares e 
redução da dor articular e facial, concluindo, portanto, que a discectomia da ATM é eficaz como primeira opção cirúrgica, visto que reduz significativamente a dor e melhora a dinâmica dos movimentos mandibulares.

Se além da perfuração do disco houver alterações degenerativas extensas do côndilo ou da fossa (erosão, cistos subcondrais), em adição a discectomia é viável realizar simultaneamente a ressecção condilar com posterior substituição total da articulação (Machoñ et al., 2020).

Sob outra perspectiva, a engenharia tecidual tem oferecido, recentemente, estratégias promissoras para pacientes que sofrem de degeneração do disco, principalmente durante os estágios iniciais da degeneração, como afinamento ou perfuração do disco, com destaque para criação de arcabouços teciduais para discos da ATM com uso de policaprolactona impressa tridimensional (3D), matriz extracelular descelularizada (ECM) e outros polímeros (Vapniarsky et al., 2018).

\subsection{Deslocamentos do disco}

\subsubsection{Deslocamento do disco com redução}

No funcionamento normal da ATM, o disco articular deve acompanhar o côndilo durante os movimentos excursivos de protusão e lateralidade e isso é possível devido a alguns fatores como a morfologia da porção central do disco que é significativamente mais fina em comparação com suas bordas (Paiva, 2008), como também a pressão interarticular (entre as superfícies articulares) que permite que o côndilo se mantenha, justamente, na zona intermediária mais delgada do disco (Okeson, 2007).

Nesse âmbito, uma relação anormal do disco articular com o côndilo mandibular, fossa e eminência articular é denominada de deslocamento do disco articular (Vilar et al., 2020; Paiva, 2008). Oito posições anormais podem ser constatadas, entre elas: deslocamento anterior completo, deslocamento anterior parcial lateral, deslocamento anterior parcial medial, deslocamento rotacional ântero-medial, deslocamento rotacional anterolateral, deslocamento medial, deslocamento lateral e deslocamento posterior (Vilar et al., 2020).

Os deslocamentos de disco funcionais são categorizados em com e sem redução (Costa et al., 2019), isto é, com ou sem reposicionamento anatômico do disco durante a manobra de abertura de boca (Abbehusen, 2019). Para melhor explicar, no deslocamento do disco com redução (DDCR), essa estrutura articular move-se anteriormente à cabeça condilar durante o movimento de fechamento da boca e volta a assumir seu posicionamento entre as superfícies condilares no momento da abertura (Young, 2015). Sendo assim, a relação disco/côndilo é alterada com a boca fechada, mas torna-se normal quando a boca está completamente aberta (Vilar et al., 2020). De modo contrário, no deslocamento de disco sem redução (DDSR), o disco está anterior ao côndilo quando a boca está fechada e não retorna à sua posição normal mesmo quando ocorre a sua abertura (Kumar et al., 2015).

As alterações do disco articular possuem caráter progressivo e são classificadas em 4 estágios clínicos consecutivos:

Estágio 1: Deslocamento do disco articular com redução; Estágio 2: Deslocamento do disco articular com redução e travamento fechado intermitente; Estágio 3: Deslocamento do disco articular sem redução; Estágio 4: Deslocamento do disco articular sem redução com evidência de perfuração do disco ou doença articular degenerativa (Bavaresco et al., 2020).

O deslocamento de disco da ATM pode estar associado à má oclusão dentária, traumas e alterações da zona bilaminar posterior que contêm estruturas ligamentares de suporte do disco articular (Abbehusen, 2019). Além disso, a etiologia desse desarranjo articular pode ter relação com: a pressão exacerbada na ATM que pode provocar a supressão do líquido sinovial e contribuir para a adesão do disco à fossa; distensão e gradativo alongamento dos ligamentos discais quando o disco está fixado na fossa, possibilitando o deslocamento; processo de afinamento do bordo posterior do disco que favorece seu deslocamento para anterior. No que se refere às causas odontológicas, pode-se citar, entre as mais comuns: a parafunção (excesso de carga no 
conjunto côndilo-disco e fossa mandibular), ausência de suporte dentário (reposicionamento do côndilo) e interferência oclusal (sobrecarga da ATM) (Neto et al., 2013).

Nos casos de deslocamento com redução pode haver a deformação do disco articular, com modificação de sua morfologia bicôncava, além da produção de sobrecarga mecânica que torna a articulação dolorida (Lin et al., 2012). Essa condição também é associada à estalidos (Vilar et al., 2020). Dessa forma, durante o movimento de translação, é gerado um som articular chamado de estalido de redução devido ao retorno do disco deslocado para uma posição de maior normalidade após o côndilo recapturá-lo. Em contrapartida, um estalido recíproco é produzido quando ocorre o deslocamento discal incorreto, isto é, anterior ao côndilo (Paiva, 2008). Ademais, o deslocamento dessa estrutura pode resultar em diminuição do espaço articular, artrite, reabsorção condilar, inflamação, além de dor e disfunção (Schiffman et al., 2014).

Clinicamente, os pacientes com DDCR experimentam uma limitação da amplitude de abertura de boca e no momento em que o disco é reposicionado, verifica-se um desvio de trajetória deste movimento, acompanhado de ruído articular intenso e brusco, audível no momento da recaptura (Dawson, 2008). Sendo assim, é possível formular a hipótese diagnóstica dessa desordem a partir da auscultação desse efeito sonoro, bem como pela observação desse desvio momentâneo da linha média durante o movimento de abertura bucal em direção ao lado afetado (Leeuw, 2008; Khalighi et al., 2016). Ademais, por meio do exame da palpação é possível sentir a mudança na posição do disco (Leeuw, 2008).

Contudo, é válido salientar que nem todos os casos de deslocamentos de disco da ATM são passíveis de diagnóstico clínico em razão de não apresentarem sinais e sintomas clínicos. Portanto, os deslocamentos de disco assintomáticos são diagnosticados por exames de imagem como ressonância magnética nuclear (Valle et al., 2015); podemos observar um exemplo na Figura 3. Tal método diagnóstico é o padrão ouro de imagem para a avaliação de patologias relacionadas à disfunção da ATM, uma vez que promove uma excelente diferenciação anatômica entre os tecidos fibrocartilagionosos, musculares e ósseos regionais, delimitando facilmente o disco articular, tanto no estudo estático em posição de boca fechada, quanto durante a movimentação dinâmica de abertura bucal. Por conseguinte, para o diagnóstico através desse exame são realizadas imagens sagitais nas fases de boca fechada e de abertura máxima, colocando-se um espaçador bucal (Abbehusen, 2019). Caso a ressonância se encontre indisponível, a artrografia surge como alternativa mais precisa de exame para confirmar o deslocamento anterior do disco articular (Tvrdy, 2007).

Figura 3 - Deslocamento do disco com redução. (A) Ressonância magnética em posição de boca fechada, nota-se que o disco articular (seta amarela) está deslocado anteriormente ao côndilo. (B) Ressonância magnética em posição de boca aberta, observe que o disco (seta amarela) retorna para a área intermediária, ocorrendo assim, o processo de recaptura dessa estrutura durante a abertura bucal.

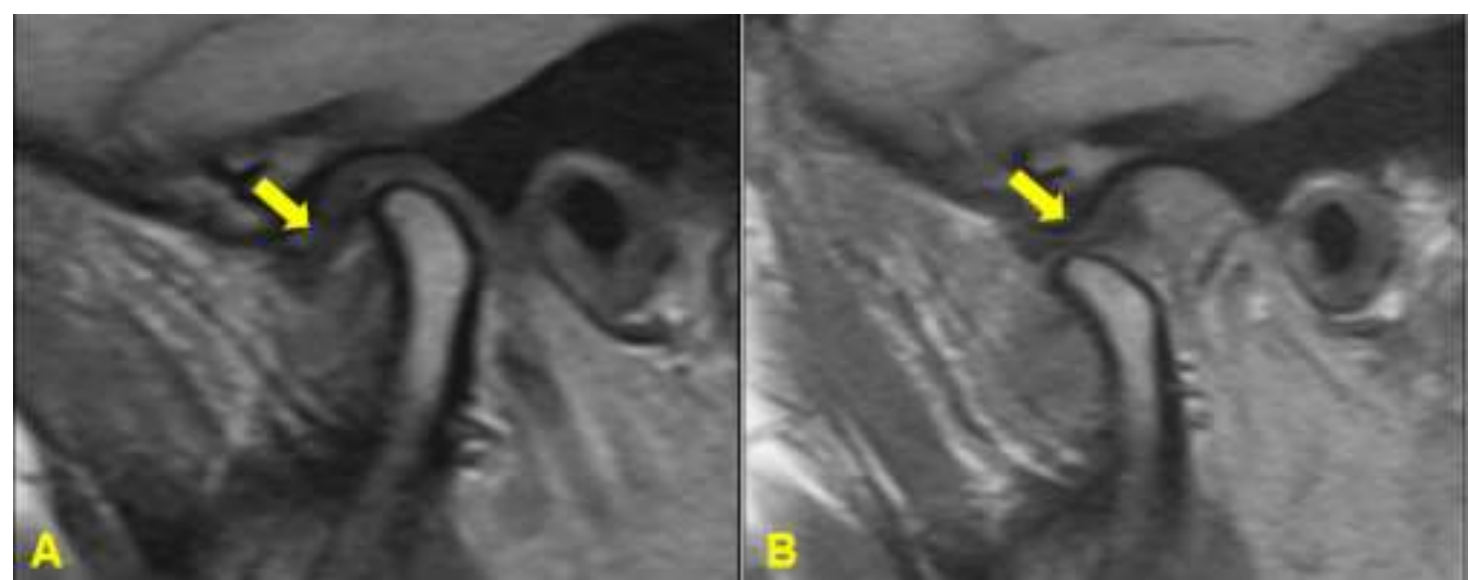

Fonte: (Poluha et al., 2019). 
Clinicamente, o DDCR pode ser ponderado de três formas: 1) como um achado clínico, quando o paciente não apresenta queixas e o estalido é identificado durante a inspeção manual profissional da ATM ou o deslocamento do disco é diagnosticado por exame de ressonância magnética e apenas orientações ao paciente são suficientes; 2) como queixa principal do paciente, quando o ruído o motiva a buscar tratamento e o plano de tratamento deve contemplar opções para reduzir/eliminar o clique; 3) quando o clique é acompanhado de artralgia e o plano de tratamento deve estar focado na melhora da dor (Poluha et al., 2019).

Dessa maneira, fica evidente que as abordagens terapêuticas devem estar relacionadas à gravidade da alteração apresentada pelo paciente e sua implicação clínica (Bavaresco et al., 2020), visto que muitas pessoas podem manter a funcionalidade da ATM confortavelmente mesmo com discos deslocados. Portanto, a seleção do tratamento depende não apenas da condição das estruturas articulares, mas também da reação do paciente (Dawson, 2008).

O tratamento do DDCR, principalmente quando o ruído é a queixa, para a grande maioria dos indivíduos, a explicação da situação, juntamente com a prevenção de atividades de sobrecarga, é a melhor opção. Já na ausência de queixas, nenhum tratamento é recomendado. É importante ressaltar que ainda não há tratamento padrão ouro para cliques na ATM. Assim, quando os pacientes reclamam dos ruídos (cliques) e buscam tratamento, as abordagens conservadoras são sempre a primeira escolha, entre elas estão: educação do paciente (como a explicação sobre o deslocamento e orientação para evitar boca aberta excessiva), exercícios, técnicas de relaxamento e talas oclusais (Poluha et al., 2019).

Por outro lado, os discos deslocados que provocam sensação dolorosa requerem tratamento (Young, 2015) que, inicialmente, consiste de farmacoterapia com o uso de anti-inflamatórios não esteroides (AINES) (Schmidseder, 2007). Quando os AINES são ineficazes para aliviar a dor, os esteróides podem ser utilizados, contudo, por um período de tempo restrito (Schiffman et al., 2014).

Os métodos invasivos devem ser considerados apenas após tentativas malsucedidas de terapias mais conservadores no que se refere à persistência das queixas e, raramente são indicados para deslocamento do disco com redução, quando se consideram os ruídos. Essas modalidades englobam artrocentese da ATM, artroscopias e técnicas cirúrgicas. Os procedimentos cirúrgicos sempre envolvem alguns riscos, como extravasamento de líquido para o tecido circundante, lesão do nervo facial, lesão óptica, hematoma pré-auricular, fístula arteriovenosa, perfuração transarticular, perfuração intracraniana, hematoma extradural e problemas intra-articulares pós-cirúrgicos, que justificam a cautela do médico em recomendar qualquer um desses procedimentos como rotina ou primeira escolha de tratamento (Poluha et al., 2019).

Em adição, nos últimos anos, o ácido hialurônico (AH) foi sugerido como um agente terapêutico alternativo para o tratamento de distúrbios internos da ATM (Goiato et al., 2016). Nesse cenário, Korkmaz et al. (2016), compararam a eficácia de uma única injeção de $\mathrm{AH}$, uma injeção dupla de $\mathrm{AH}$ e terapia com tala para o tratamento de deslocamento do disco com redução. Os resultados desse estudo constataram que a injeção de $\mathrm{AH}$ e estabilização com talas são modalidades aceitavelmente bem-sucedidas de tratamento para aliviar os sinais e sintomas clínicos desse tipo de deslocamento (a injeção dupla de AH parece ser superior), especialmente na redução do ruído articular.

\subsubsection{Deslocamento do disco sem redução}

O desenvolvimento do desarranjo interno da ATM é capaz de evoluir de uma etapa incipiente (com redução) para uma avançada (sem redução) (Ikeda \& Kawamura, 2013). Nesse sentido, o deslocamento do disco sem redução (DDSR) é um distúrbio articular em que o disco se desloca anteriormente em relação ao côndilo quando a boca está fechada, não retornando à sua posição de normalidade mesmo durante a abertura bucal (Kumar et al., 2015), ou seja, o disco permanece fixo anteriormente tanto na posição de boca fechada quanto na posição de boca aberta, também conhecido como deslocamento anterior sem recaptura discal (Abbehusen, 2019). 
Esse distúrbio representa o grau mais severo de desarranjo articular interno, em comparação com o deslocamento do disco com redução (DDCR), visto que é comum se observar alterações degenerativas no disco, como irregularidade de contornos e redução das suas dimensões, bem como sinais de ruptura de ligamentos da banda posterior (Abbehusen, 2019). Alterações ósseas, como erosão, facetamento, formação de osteófitos e esclerose também estão frequentemente associados ao DDSR (Vilar et al., 2020). Os possíveis fatores causais que possivelmente estão associados a ocorrência dos deslocamentos de disco já foram descritos na sessão anterior (Deslocamento do disco com redução).

No que se refere aos sintomas e características clínicas, dor acentuada e limitação dos movimentos mandibulares são os relatos mais frequentes de pessoas com deslocamento agudo de disco da ATM sem redução (Litko et al., 2017). A sensação dolorosa presente, muitas vezes, está especialmente relacionada à tentativa de abertura bucal além do ponto de restrição (Pinto et al., 2012; Schmidseder, 2007). Outro aspecto clínico que pode ser encontrado, em pacientes com DDSR, é a presença de uma deflexão mandibular, como pode ser observado na figura 4, para o lado ipsilateral durante a abertura e protusão e restrição para o lado contralateral do deslocamento (Okeson e Leeuw, 2011; Vilar et al., 2020; Pinto et al., 2012; Paiva, 2008). Adicionalmente, sinais sonoros de crepitação também podem ser evidenciados clinicamente durante o movimento articular (Neto et al., 2013; Vilar et al., 2020).

A Figura 4 demonstrada acima representa um movimento de abertura bucal, em deflexão. A deflexão é um efeito que se caracteriza por qualquer mudança na trajetória da linha média que se torna maior com a abertura e não desparece com a abertura máxima. Esse achado clínico é comum em pacientes com deslocamento do disco sem redução. Note na imagem que não ocorre o retorno da linha média, ela permanece descentralizada (linhas brancas) durante a abertura bucal. Desse modo, a mandíbula deflete para o lado da articulação acometida (nesse caso o lado direito) e geralmente, ocorrem movimentos excêntricos relativamente normais no lado ipsilateral, enquanto no lado contralateral os movimentos são restritos.

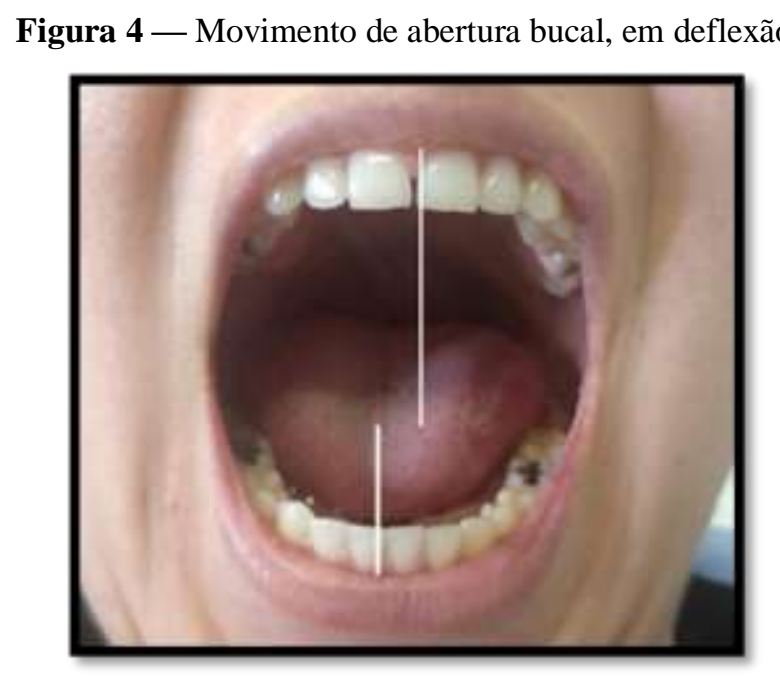

Fonte: Lima (2019).

O diagnóstico de DDSR é fundamentado em uma combinação da história, exame clínico e achados da ressonância magnética, que mostra a localização e a forma do disco na posição de boca aberta e fechada, demostrada na figura 5, derrame articular e quaisquer alterações degenerativas na articulação (Renapurkar, 2018). No entanto, em pacientes com DDSR sem abertura limitada, o diagnóstico clínico é mais difícil, visto que existem poucos sinais e sintomas e as vezes eles não se lembram se têm uma história de sintomatologia e ainda, quando não há limitação de abertura, é trabalhoso diferenciar DDSR da ATM normal, principalmente em pacientes jovens com apenas uma articulação afetada (Giraudeau et al., 2017). O 
diagnóstico precoce contribui substancialmente para uma melhor resposta terapêutica e pode prevenir artrose secundária da ATM (Abbehusen, 2019).

$\mathrm{Na}$ Figura 5 a seguir, podemos observar o deslocamento do disco sem redução. Na imagem do corte sagital analisa-se que o disco (seta branca) continua deslocado, não retornando à sua posição anatômica de normalidade, evidenciando, portanto, o diagnóstico de deslocamento do disco sem redução.

Figura 5 - Deslocamento do disco sem redução. (A) Detalhe de corte sagital de ressonância magnética da ATM direita em posição de boca fechada, evidenciando deslocamento do disco articular (seta branca). (B) Corte sagital de ressonância magnética da ATM direita na abertura máxima da boca.

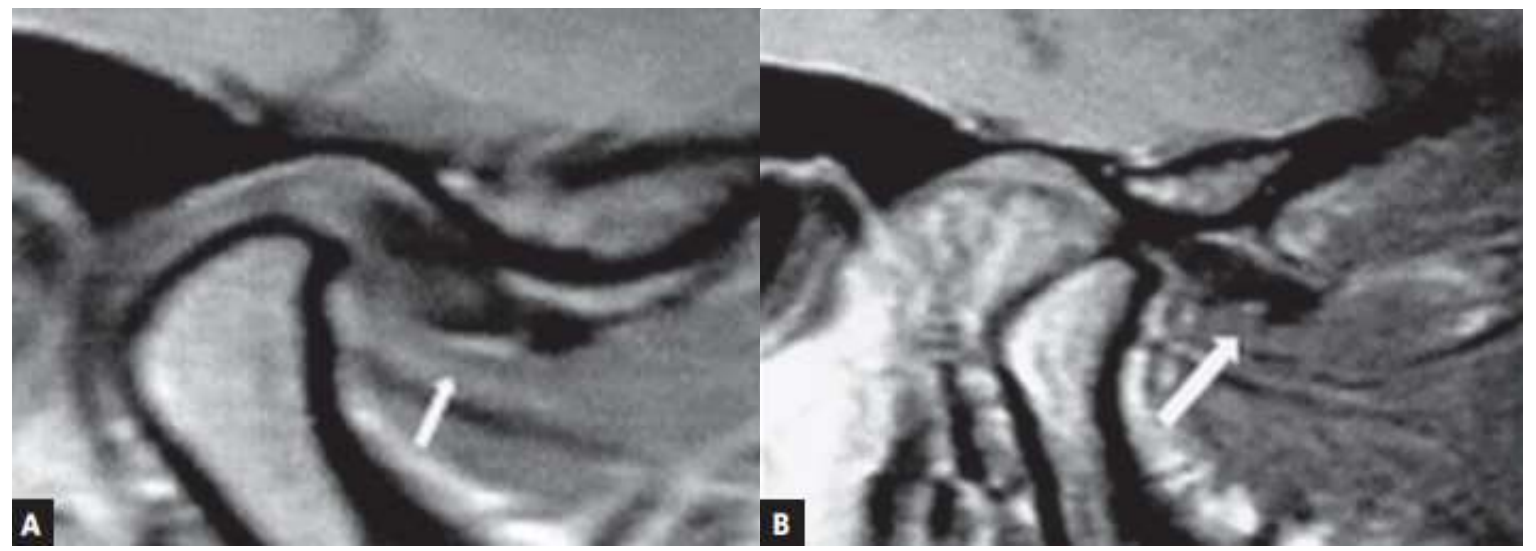

Fonte: Junior et al, (2015).

Nesse mesmo contexto, a avaliação da translação condilar por meio da palpação do polo lateral do côndilo é muito útil para o diagnóstico clínico de DDSR (Giraudeau et al., 2017). Quando a palpação da articulação acometida tem uma resposta dolorosa, isso indicia, justamente, a translação restrita do côndilo obstruído (Leeuw, 2008). Sob outra perspectiva, a axiografia computadorizada é um método que permite a análise precisa das translações condilares (Giraudeau et al., 2017). Ainda assim, para a confirmação do diagnóstico de DDSR deve ser feita uma ressonância magnética (Neto et al., 2013).

As modalidades existentes para tratar o DDSR podem ser tanto conservadoras como cirúrgicas (Okeson, 2007). Os tratamentos conservadores são considerados a primeira opção terapêutica para pacientes com DDSR, e os tratamentos com exercícios e terapia manual são amplamente utilizados nesta área (La Touche et al., 2020). Nesse cenário, em deslocamento anterior do disco sem redução, onde o paciente trava de boca fechada, deve-se tentar a recaptura ou redução do disco através de manipulação manual (Schmidseder, 2007; Breton-Torres et al., 2016). Inicialmente, é feita a anestesia infiltrativa local e o profissional deve solicitar ao paciente que lateralize a mandíbula para o lado contralateral do deslocamento e se não houver recaptura é necessária manipulação. Essa manobra consiste em forçar a mandíbula para baixo e para frente. Após isso, o paciente deve fazer movimentos sequenciais e fechar a boca em topo, pois a oclusão em máxima intercuspidação pode recidivar o deslocamento do disco. Com isso, a placa de reposicionamento anterior deve ser instalada no momento da redução do disco. Em caso em que não houver recaptura do disco, a manobra pode ser repetida ou então ser efetuada artrocentese assim que possível (Breton-Torres et al., 2016).

No geral, o tratamento do desarranjo articular interno da ATM envolve uma esfera multidisciplinar de profissionais e podem ser administrados analgésicos, fisioterapia, drogas para relaxamento muscular, como a toxina botulínica e ainda, placas odontológicas. Se as opções terapêuticas citadas não surtir efeito, injeções intra-articulares de corticoide e cirurgia podem ser necessárias (Abbehusen, 2019). Uma das intervenções cirúrgicas existentes nesse ramo é a discopexia ou discoplastia que envolve uma artrotomia seguida de reparo/remodelagem e/ou reposicionamento do disco intra-articular (Renapurkar, 2018). 
Por outro lado, a artrocentese é uma cirurgia articular minimamente invasiva e com significativa eficácia para reduzir a dor, aumentar a distância interincisal máxima, eliminar o derrame articular, bem como revigorar a saúde bucal referente à qualidade de vida dos pacientes acometidos por distúrbios da ATM (Chandrashekhar et al., 2015; Song e Yap, 2018). Outros procedimentos cirúrgicos viáveis englobam além da artrocentese, artroscopia e cirurgias abertas da articulação (Dimitroulis et al., 2010).

Outra abordagem terapêutica que está sendo estudada para o tratamento de deslocamentos de disco é a viscossuplementação. Tal método utiliza o ácido hialurônico, que é um polissacarídeo presente no líquido sinovial e na matriz extracelular dos tecidos conectivos. Seu mecanismo de ação baseia-se lubrificando a articulação, reduzindo a fricção no espaço intra-articular e diminuindo o aparecimento de adesões, como também age na diminuição dos mediadores inflamatórios, promovendo assim, o alívio da dor (Dantas et al., 2019).

Bonotto et al. (2014) discutiram a técnica de viscossuplementação no tratamento das alterações internas da ATM em 55 pacientes com deslocamento do disco com redução (DDCR) e DDSR. Os resultados mostraram aumento significativo de abertura bucal em todos os grupos e se mantiveram constantes ao longo de quatro meses de acompanhamento. Portanto, os autores afirmaram que a viscossuplementação com ácido hialurônico (AH) pode ser considerada uma boa alternativa no restabelecimento funcional da ATM, em curto prazo, em pacientes com alterações internas da ATM que não responderam aos tratamentos conservadores.

\subsection{Deslocamento do complexo disco-côndilo (luxação e subluxação da mandíbula)}

\subsubsection{Hipermobilidade}

A hipermobilidade da ATM corresponde à hipertranslação do côndilo mandibular anterior à eminência articular durante a abertura bucal excessiva (Liddell e Perez, 2015), em outras palavras, esse distúrbio ocorre no momento em que o complexo disco-côndilo sofre uma superextensão, ou seja, ultrapassa a eminência articular durante a abertura da boca (Leeuw, 2008; Tuijt et al., 2018). Os distúrbios de hipermobilidade da ATM podem ocorrer naturalmente ou ser um sinal indicativo de instabilidade articular, sendo classificados conforme seu modo de redução como subluxação ou luxação (Tuijt et al., 2018).

Nesse contexto, a subluxação resulta na translação do côndilo mandibular além da eminência articular. Esse movimento do côndilo para frente ocorre no final da abertura e reflete a ausência de limitação do movimento translacional e é passível de redução espontânea na fossa glenóide (Tuijt et al., 2018). Em contrapartida, a luxação ocorre quando o côndilo se move para fora da fossa glenóide, fixando-se no aspecto ântero-superior da eminência articular, onde não pode ser autoreduzido (Melo et al., 2017). Isso pode provocar um bloqueio da mandíbula na posição aberta, impedindo o paciente de fechar a boca (Tuijt et al., 2018). A luxação pode ser bilateral ou unilateral (Neto et al., 2013) e ocorrer anterior, posterior, superior ou lateral à eminência articular. As luxações também podem ser classificadas como agudas, crônicas ou recorrentes (Hillam e Isom, 2020).

A luxação da ATM pode ser resultante de etiologias atraumáticas ou como resultado de trauma na mandíbula. Os fatores que levam à luxação atraumática podem incluir qualquer ato que resulte em abertura excessiva e forçada da mandíbula, como bocejos, convulsões ou mastigação repetida, bem como causas anatômicas subjacentes, como frouxidão ligamentar, anatomia aberrante ou distúrbios do tecido conjuntivo. As causas atraumáticas podem incluir atividades diárias muito comuns, como rir, bocejar, cantar, vomitar e beijar. Reações distônicas (por exemplo, tétano) e efeitos colaterais extrapiramidais também são possíveis causas atraumáticas. Já as causas iatrogênicas incluem tratamentos dentários, intubação endotraqueal, broncoscopia e laringoscopia. O trauma facial agudo, por sua vez, é uma das causas mais comuns de luxação (Hillam e Isom, 2020; Liddell e Perez, 2015). 
Os fatores de risco para luxação da ATM são importantes na identificação das possíveis causas e do risco de recorrência. Os fatores de risco incluem luxação anterior, déficits estruturais ou anatômicos, doenças do tecido conjuntivo que afetam a estabilidade (por exemplo, síndrome de Marfan, síndrome de Ehler-Danlos, distrofia muscular, distrofia orofacial), distúrbios neurodegenerativos ou neurodisfuncionais (por exemplo, doença de Huntington, esclerose múltipla ou epilepsia), aumento da idade e alterações na dentição do paciente (Hillam e Isom, 2020).

Usualmente, a subluxação gera um som que pode ser recíproco, isto é, capaz de manifestar-se tanto ao abrir quanto ao fechar a boca. Contudo, diferentemente do caso de desarranjo de disco, esse som normalmente ocorre no fim da fase de abertura (quase na abertura máxima) e no começo da fase de fechamento. Sendo assim, essa condição pode ser habitual, o que significa que o complexo disco-côndilo passa a eminência para frente e para trás sem causar, dor, desconforto ou disfunção durante a abertura de rotina (Leeuw, 2008).

Já em casos de luxação da ATM, os principais sintomas apresentados pelos pacientes incluem oclusão prejudicada, dor e incapacidade de fechar a mandíbula após ampla abertura bucal (Marqués-Mateo et al., 2016; Bag et al., 2014). Em adição, o prognatismo da mandíbula, mordida cruzada anterior e mordida aberta são características clássicas das luxações bilaterais da articulação. Enquanto o desvio mandibular que define uma mudança na linha média para o lado não afetado e a mordida cruzada no lado acometido são prevalentes em situações unilaterais (Akinbami, 2011).

No diagnóstico de luxação mandibular aguda, o paciente tem história de trauma ou hiperextensão da articulação e, se bilateral, incapacidade de fechar a boca (portanto, má oclusão aguda evidente). Se unilateral, a má oclusão aguda é caracterizada por um claro desvio da mandíbula para o lado não deslocado. O côndilo deslocado não é palpável na cavidade articular. Já os casos de luxação crônica podem ser um pouco mais difíceis de reconhecer. Apesar da má oclusão também ser muito evidente, o paciente pode ter se acostumado e simular uma má oclusão com componente esquelético. Portanto, anamnese, inspeção e radiologia estabelecem o diagnóstico diferencial (de la Torre Molina \& Cabrera Velázquez, 2018).

Assim, a imagem panorâmica pode ser útil para identificar a luxação da ATM. Entretanto, caso esse recurso não esteja à disposição, as radiografias simples que fornecem vistas anteroposterior, bilateral e submental também podem ser empregadas para auxiliar no processo de detecção. Especificamente, o profissional prioriza visões panorâmicas, transfaríngeas, transcranianas e submentais (White et al., 2016).

Na hipótese de as radiografias simples revelarem resultados negativos e apesar disso o profissional ainda suspeitar da luxação, a tomografia axial computadorizada é viável para cooperar na avaliação da ATM, bem como da face óssea. Em contraste, a ressonância magnética não é um método frequentemente utilizado para avaliar a luxação da articulação, embora seja indicada para analisar alterações articulares crônicas e desarranjo interno (White et al., 2016).

Geralmente, a subluxação é uma condição que não requer tratamento, embora nos casos em que cause artralgia, uma restrição voluntária de abertura máxima deva ser feita (de la Torre Molina \& Cabrera Velázquez, 2018). Nos casos de subluxação com quadro de dor associada ou deslocamento da cabeça da mandíbula por repetição no qual o tratamento clínico produziu pouca ou nenhuma resposta adequada, a tuberculotomia também pode ser indicada. Esse procedimento objetiva a remoção ou redução do tubérculo articular, no qual se procura alterá-lo no sentido látero-medial, propiciando uma superfície plana e suave. Com isso, evita-se o travamento da cabeça da mandíbula junto a vertente anterior desse tubérculo (Valle et al., 2015).

Por outro lado, para luxações agudas da ATM, a manipulação da mandíbula em uma direção ligeiramente para frente e depois para baixo afim de que o complexo disco-côndilo retorne à fossa é a forma de tratamento mais conveniente (Leeuw, 2008; Tuijt et al., 2018). Essa manobra de reposicionamento mandibular pode, em alguns casos, exigir a analgesia com a finalidade de obter relaxamento muscular. Contudo, antes da tentativa de qualquer manipulação, deve ser priorizado o aconselhamento a respeito do problema, visto que alguns pacientes demonstram significativa ansiedade (Schmidseder, 2007). 
As técnicas de redução incluem técnicas intraorais e técnicas extraorais. As técnicas intraorais incluem a posição bimanual, pivô de punho e posição reclinada. As técnicas extraorais protegem os dedos do clínico de serem mordidos. As técnicas extraorais incluem o método do reflexo de vômito, o método da seringa e a abordagem externa (Hillam e Isom, 2020).

Sob outra perspectiva, as luxações crônicas podem ser gerenciadas através de modalidades de tratamento minimamente invasivo ou cirúrgico (Liddell e Perez, 2015). Dessa forma, as abordagens conservadoras englobam a limitação da excursão do côndilo, incluindo a fisioterapia, injeções esclerosantes intra-articulares que promovem a fibrose articular e o uso de toxina botulínica tipo A. Contudo, esses tratamentos dificilmente são bem-sucedidos e, em função disso, a cirurgia é recomendada de maneira frequente (Sharma, 2012).

A injeção de toxina botulínica A pode ser usada com outras técnicas ou como terapia primária. 25 a 50 unidades dessa substância são injetadas diretamente no pterigóide lateral para prevenir luxações recorrentes. As injeções podem ser repetidas a cada 3 a 6 meses para melhorar os resultados e reduzir a morbidade. O mecanismo de ação bloqueia a liberação de acetilcolina da junção neuromuscular, bloqueando a liberação mediada pelo cálcio. O resultado do bloqueio da liberação de acetilcolina é um enfraquecimento temporário do músculo. O uso da toxina foi relatado como uma opção de tratamento razoável e segura para uso na população pediátrica com luxação recorrente da ATM (Hillam e Isom, 2020).

Em caso de mais de três episódios de luxação no período de seis meses, a terapia cirúrgica de eleição é a eminectomia (Breton-Torres et al., 2016). Essa técnica apresenta-se como a primeira escolha de tratamento nos casos de luxação recidivante, em virtude de preservar a estrutura articular e a simplicidade de execução. Desse modo, aumenta-se o espaço articular, promovendo a melhor acomodação do disco. A dissecção vai até o limite da cápsula e eminência articular e complicações relacionadas a hemorragias são preocupantes nessa região, bem como lesões nervosas. É de suma importância não deixar irregularidades superficiais para não haver recidivas (Vilar et al., 2020). No entanto, resultados a longo prazo revelaram que, mesmo após a realização desse procedimento cirúrgico, o côndilo pode permanecer se deslocando e ainda provocar danos articulares, induzindo à disfunção dolorosa da ATM (Medra e Mahrous, 2008).

Em suma, é ideal que a indicação do tratamento cirúrgico seja fundamentada no tipo do deslocamento, no mecanismo, na etiopatogênese, nos fatores predisponentes, na morfologia óssea, na idade do paciente e na capacitação da equipe médicoodontológica (Akinbami, 2011).

\subsection{Condições Inflamatórias}

As patologias inflamatórias da articulação temporomandibular (ATM) são desordens intra-articulares comuns. Apesar da sua etiologia ainda não estar bem esclarecida, acredita-se que um dos principais fatores relacionados são os traumas (microtrauma e macrotrauma), e que estes, eventualmente, levam à formação de processos inflamatórios nas superfícies articulares (Mendes, 2012). Geralmente, as causas intra-articulares da DTM incluem desarranjo articular interno, osteoartrite, inflamação capsular, hipermobilidade e lesão traumática. Condições inflamatórias, como artrite reumatóide e espondilite anquilosante, também podem levar a distúrbios da articulação interna (Cavalcante et al., 2020).

A dor é o principal sintoma que acompanha essas condições inflamatórias, sendo este o principal motivo da procura do paciente às consultas. Normalmente, o tratamento das desordens inflamatórias temporomandibulares passa por uma abordagem multidisciplinar, farmacológica e fisioterápica. A maior parte dessas patologias são resolvidas com tratamentos reversíveis e não-invasivos, tais como: medicação sistêmica e local, terapia com laser de baixa intensidade, ultrassons, iontoforese e fonoforese (Paiva, 2008; Mendes, 2012). 


\subsubsection{Capsulite e sinovite}

A capsulite é definida como a inflamação da camada externa das fibras da cápsula articular enquanto a sinovite é a inflamação do revestimento sinovial interno. Em razão de compartilharem características clinicamente semelhantes esses distúrbios são considerados, como, uma única entidade clínica (Neto et al., 2013). Essas condições inflamatórias são resultantes de trauma, irritação ou infecção e estão associadas, de forma frequente, à outras DTMs (Paiva, 2008).

A capsulite pode ser decorrente de um trauma mandibular que provoca, consequentemente, um alongamento excessivo da cápsula articular, tendo assim dor ao exercer função, dor à palpação e limitação de movimentos (Robin, 2015). Já a inflamação da membrana sinovial ocorre, principalmente, por força excessiva na ATM o que é capaz de levar ao excesso de alongamento e entorse da cápsula e do ligamento articular, bem como do tecido circundante do disco e ainda, osteoartrite da articulação (Ibi, 2019).

Nesse contexto, o sintoma preponderante dessas alterações inflamatórias é a dor em repouso, que pode se acentuar no decorrer de sua função e à medida que a articulação sofre pressão (Neto et al., 2013). Além da dor, o inchaço e a perda de movimentos articulares, geralmente acompanhados de derrame, também, representam indicativos de sinovite e a manutenção, isto é, o não tratamento dessa condição pode resultar na degeneração da cartilagem e contribuir diretamente para a progressão da osteoartrite (Berenbaum, 2013).

Especificamente, no quadro de sinovite, além da dor aguda localizada na ATM, também ocorre uma redução da translação da articulação afetada, ou seja, verifica-se uma diminuição da distância máxima de abertura interincisal, observa-se um desvio da mandíbula em direção ao lado afetado pela abertura e redução da excursão lateral para o lado contralateral. No caso de edema intra-articular significativo associado à sinovite, pode haver comprometimento da oclusão com uma mordida aberta posterior ipsilateral e um desvio da linha média mandibular em direção ao lado contralateral em repouso. Ademais, deve ser considerada a ocorrência mioespasmo dos músculos mastigatórios circundantes (masseter e músculos temporais, que se tornam muito sensíveis à palpação) à medida que o corpo tenta limitar os movimentos da articulação lesada (Israel, 2016).

No que se refere ao diagnóstico clínico dessas condições inflamatórias, a palpação lateral da ATM é muito útil (Ifteni et al., 2016; Paiva, 2008). Nesse exame, as pontas dos dedos são colocadas sobre os aspectos laterais de ambas as articulações simultaneamente. Caso o profissional esteja incerto sobre a posição correta dos dedos, ele deve solicitar ao paciente para abrir e fechar a boca algumas vezes. Deve-se sentir os polos laterais dos côndilos e os trajetos para frente e para baixo. Posteriormente, deve-se pedir para o paciente relaxar, aplicar uma força medial nas áreas articulares logo após e estar atento caso o examinado relate qualquer sintoma. $\mathrm{Na}$ abertura máxima os dedos devem rotar ligeiramente para posterior e, se o paciente acusar dor, a hipótese diagnóstica provável é de capsulite ou retrodiscite (Ifteni et al., 2016).

Para confirmação do diagnóstico, pode-se recorrer à ressonância magnética, visto que a cápsula articular é bem vista nas imagens coronais. Em articulações normais, a cápsula pode ser observada como uma linha escura, relativamente plana e fina, localizada lateralmente ao côndilo. Em articulações com deslocamentos laterais do disco, é comum observar o seu espessamento. Em pacientes com edema e dor na região articular, imagens têm mostrado aumento de fluido na cápsula articular, sugestivo de edema capsular. Essas observações, portanto, são sugestivas de capsulite (Vilar et al., 2020).

Por outro lado, o inchaço palpável das articulações gerado pelo espessamento da sinóvia ou do extravasamentodo líquido sinovial representa um importante sinal para detectar clinicamente a sinovite (Krasnokutsky et al., 2008). Sendo assim, a palpação lateral da ATM é um método que possibilita a intensificação dos sintomas (Paiva, 2008). Embora atualmente, a reação inflamatória nos tecidos sinoviais de paciente que apresentam dor na ATM possa ser detectada por meio de estudos artroscópicos e histopatológicos de maior confiabilidade (Takeda et al., 2012).

As condutas de tratamento para esses distúrbios inflamatórios são dependentes, em grande parte, da etiologia. A limitação funcional da mandíbula, o uso de analgésicos (não esteroides) e calor úmido ou ultrassom na articulação são 
recomendados quando um macrotrauma for o fator iniciador e que não será repetido. De outra forma, quando a inflamação está associada a microtrauma crônico, uma terapia mais definitiva pode ser indicada, como o uso de uma placa articular (Neto et al., 2013).

Quando as condutas mais conservadores não produzem os resultados desejados, pode recorrer-se à artrocentese, que tem como objetivo a irrigação e lavagem da cavidade articular, de preferência da cavidade superior por ter um acesso mais fácil, a fim de reduzir mediadores inflamatórios e eliminar aderências fibrosas, ajudando a promover a reparação tecidual (Bas et al., 2019), pois a introdução do líquido sob pressão, leva a um aumento do espaço articular, e à consequente lavagem e remoção de mediadores inflamatórios e catabólicos. Essa técnica está indicada em casos de limitação da abertura de boca, sinovite ou capsulite, existência de aderências discais em fase inicial, próximas da fossa superior do tubérculo articular e deslocamento anterior do disco, havendo ou não redução (Malachovsky et al., 2019).

\subsubsection{Retrodiscite}

O tecido retrodiscal da ATM é composto por fibras colágenas frouxamente associadas, um complexo ramificado de fibras elásticas, reservas de gordura, suprimento sanguíneo arterial especializado, um amplo plexo venoso e linfático, além de um considerável suprimento nervoso (Katzberg e Tallents, 2005).

Diante do contexto, devido à sua vasta vascularização e inervação, os tecidos retrodiscais não suportam forças excessivas. Sendo assim, um processo inflamatório acometendo essas estruturas, denominado de retrodiscite, pode ser desencadeado caso haja alteração súbita ou crônica do côndilo na fossa mandibular (Neto et al., 2013). Esse dano retrodiscal tem como principal fator etiológico o trauma local (agudo ou crônico) ou esforço repetitivo (que também pode ocasionar um deslocamento do disco) (Robin, 2015).

Dessa forma, indubitavelmente, os distúrbios da ATM não afetam somente os tecidos do disco ou do osso, mas também são capazes de promover inflamação ou adesão fibrótica no tecido retrodiscal (Lee e Yoon, 2009).

A retrodiscite causa dor contínua suscetível à intensificação perante hábitos parafuncionais como o apertamento. Além disso, diante da presença de edema, o côndilo pode ser compelido anteriormente, tendo como resultado uma mal oclusão repentina evidenciada, clinicamente, como desoclusão dos dentes posteriores no lado inflamado, e, no contato prematuro dos dentes anteriores no lado contrário (Neto et al., 2013). A sensação dolorosa, por sua vez, é acentuada durante a palpação quando a boca está aberta e reduzida quando interposto um dispositivo entre os dentes em oclsuão, do lado afetado (Robin, 2015).

O método de palpação lateral e posterior da ATM pode ser empregado visando estipular o comprometimento dos tecidos periarticulares. Dessa maneira, o ato de palpar bilateralmente tem como objetivo detectar qualquer sensibilidade provocada pelo processo inflamatório, tendo em vista que esse evento é capaz de maximizar os sintomas clínicos desse distúrbio (Paiva, 2008; Lee e Yoon, 2009; Ifteni et al., 2016).

A retrodiscite pode ser tratada através da recomendação de um anti-inflamatório não esteroidal, compressa quente no local afetado, bem como o repouso para evitar a sobrecarga articular (Neto et al., 2013). Outro método terapêutico que alcançou popularidades nos últimos anos devido à sua natureza conservadora foi a laserterapia de baixa intensidade que é capaz de demonstrar efeitos analgésicos, regenerativos e antiinflamatórios no tecido alvo. Vários mecanismos foram propostos para a redução da dor e os efeitos terapêuticos de lasers de baixo nível, incluindo liberação de opioides endógenos, respiração celular aprimorada e cicatrização de tecidos, vasodilatação aumentada, aumento do limiar da dor ao afetar o potencial da membrana celular e diminuir a inflamação (Khalighi et al., 2016; Khiavi et al., 2020). 


\subsubsection{Artrite reumatoide da ATM}

A artrite reumatoide (AR) é uma doença inflamatória autoimune que afeta as articulações sinoviais, incluindo a ATM. Eventualmente, resultam na destruição de cartilagem e osso. Em países desenvolvidos, a AR afeta 0,5 de 1,0\% da população adulta. O tratamento farmacológico consiste em interromper a progressão da doença e aliviar os sintomas. A intervenção antecipada resulta em melhores desfechos clínicos e pode prevenir a destruição articular, o que torna o diagnóstico precoce desejável (Kroese et al., 2020).

Os sintomas da AR da ATM incluem dor, restrição na abertura bucal, travamento e ruídos, que juntos podem levar a um comprometimento significativo e consequentemente, uma piora na qualidade de vida do indivíduo portador dessa condição (Connor et al., 2017). A maioria dos pacientes com AR são afetados pela chamada forma soropositiva de AR, que é definida pela presença de anticorpos específicos: IgM fator reumatóide (IgM-RF) e anticorpos contra proteínas citrulinadas (Malmstrom et al., 2016).

O diagnóstico da AR da ATM é obtido através de exames como a ressonância magnética (RM), e mais recentemente a tomografia computadorizada de feixe cônico (TCFC) que permitem diagnosticar seus primeiros sinais (alteração do complexo disco-ligamentar, derrame intra-articular, lesões osteocondrais). O diagnóstico tardio pode ser explicado pelas características embriológicas, anatômicas e fisiológicas dessa articulação (Ferri et al., 2018).

Para o tratamento da AR da ATM, é indicado repouso da mandíbula, dieta leve, tala oclusal e terapia médica, incluindo drogas antirreumáticas modificadoras da doença e analgesia simples, são a base do tratamento inicial e irão melhorar a maior parte dos sintomas na maioria dos pacientes. Além disso, a artroscopia e a artrocentese da ATM podem ajudar a modular a dor, aumentar a abertura bucal e aliviar o travamento caso os procedimentos anteriores não sejam bem efetivados. Esses procedimentos minimamente invasivos apresentam poucas complicações e podem ser repetidos. A substituição total da ATM é reservada para pacientes nos quais ocorreu colapso ou fusão articular ou nos quais outros tratamentos não conseguiram fornecer o controle sintomático adequado. As terapêuticas apontadas produzem resultados excelentes e são aprovadas pelo Instituto Nacional de Excelência em Saúde e Cuidados (NICE), Reino Unido (Connor et al., 2017).

\subsubsection{Espondilite anquilosante da ATM}

A espondilite anquilosante (EA) é uma doença inflamatória sistêmica crônica. O envolvimento da ATM na EA varia de $4 \%$ a $35 \%$ e causa movimento restritivo da articulação, dor e incapacidade da abertura bucal. Embora a radiografia convencional possa detectar o envolvimento da ATM, a tomografia computadorizada (TC) é necessária para as relações do espaço articular e morfologia óssea. Além disso, é conveniente ressaltar a importância dos exames de imagem nessa doença, pois o diagnóstico e o tratamento precoces podem melhorar a qualidade de vida desses pacientes (Gupta et al., 2016).

$\mathrm{Na}$ EA, os sintomas não são específicos e a maioria dos pacientes não apresentam dor. As características clínicas mais frequentes são os sons da ATM, dores na musculatura mastigatória (particularmente, os músculos pterigóides laterais), hipertrofia dos masseteres e limitação de movimento manifestado como restrição da abertura bucal. Esses sinais e sintomas são vistos menos frequentemente e não são tão graves quanto aqueles encontrados na artrite reumatoide (Connor et al., 2017).

O tratamento inicial da EA da ATM é aliviar a dor, inicialmente usando medidas conservadoras, que resolverá os sintomas em mais de $80 \%$ dos pacientes. Isso inclui: repouso da mandíbula e uma dieta leve; evitar uma ampla abertura bucal; fisioterapia; anti-inflamatórios não esteroides, que podem ser prescritos topicamente; e talas oclusais macias feitas pelo dentista. O gerenciamento eficaz da atividade da doença com drogas antirreumáticas modificadoras da doença e produtos 
biológicos apropriados para a doença subjacente é vital, dado que podem atenuar, de modo eficaz, os danos nas articulações suprimindo a inflamação (Callhoff et al., 2015; Connor et al., 2017).

\subsection{Doenças Degenerativas}

\subsubsection{Osteoartrose}

As doenças articulares degenerativas são caracterizadas pela degeneração dos tecidos duros e moles ao redor de uma articulação, ocasionando dor alteração funcional (Pantoja et al., 2018; Costa et al., 2020), no caso da ATM, essas condições possuem caráter agressivo e causam alterações nas superfícies articulares ósseas do côndilo e da fossa (Neto et al., 2013; Costa et al., 2020). De acordo com Pantoja et al. (2018), a prevalência da doença articular degenerativa varia muito, dependendo dos critérios de diagnóstico, da população estudada e dos meios de avaliação da ATM. Existem relatos que essas alterações degenerativas podem anteceder o deslocamento do disco e a sua etiologia é bastante associada a traumas e ao processo do envelhecimento (Ahmad e Schiffman, 2016), bem como a eventos fisiopatológicos funcionais ou sistêmicos (Paiva, 2008).

Nesse contexto, a osteoartrose é uma doença articular crônico-degenerativa caracterizada pelo desgaste da cartilagem articular (Duarte et al., 2013), causada por um desequilíbrio homeostático do condrócito. Estruturas como o osso subcondral e a membrana sinovial também participam do desenvolvimento e da progressão dessa condição (Neto et al., 2013). Ademais, essa doença pode ser desencadeada quando a remodelação articular não é capaz de preservar o equilíbrio entre a forma e a função ou as superfícies articulares são submetidas à sobrecarga. Dessa forma, a osteoartrose, especificamente, está ligada a modificações morfológicas, em geral adaptativas, que afetam o recobrimento fibroso, zona proliferativa e a cartilagem articular. Em razão dessas estruturas não possuírem vascularização, a capacidade de gerar inflamação é inexistente (Paiva, 2008).

A etiologia da osteoartrose ainda pode ser controversa, sendo classificada em primária (idiopática) ou secundária (devido a patologias traumáticas, inflamatórias ou infecciosas). Tendo como principais fatores de riscos a obesidade, idade, predisposição genética, sexo feminino, atividades ocupacionais e exercícios repetitivos (Rodrigues et al., 2019).

Clinicamente, a mandíbula pode apresentar uma restrição de abertura bucal com deflexão para o lado afetado secundariamente às mudanças articulares. Além disso, há crepitação provocada por modificações nas superfícies da articulação durante a abertura e fechamento bucal, sendo mais provável estar presente em estágios avançados da doença. Em contrapartida, a dor e pontos sensíveis durante a palpação da articulação são ausentes (Neto et al., 2013). Desse modo, os efeitos sonoros presentes sugerem degeneração/desordens do disco articular, sendo normalmente, um indício de osteoartrose (Vilar et al., 2020).

O diagnóstico das doenças degenerativas necessita ser confirmado por meio de exames de imagem. A tomografia computadoriza exibe satisfatoriamente alterações ósseas, já a ressonância magnética auxilia na análise da posição discal, estrutural e extravasamento articular (Dias et al., 2016). Os aspectos radiológicos com as alterações ósseas podem mostrar erosão da superfície, formação de cisto subcondral, achatamento condilar, perda de espaço articular, presença de osteófitos, esclerose do osso subcondral e outras formações císticas (Schiffman et al., 2014; Rodrigues et al., 2019).

Para o estabelecimento de um plano de tratamento apropriado que visa a o processo adaptativo da articulação, fatores como a história, sintomas subjetivos, achados do exame clínico e de imagem, bem como o estágio da doença devem ser levados em consideração. Assim, métodos de tratamentos mais conservadores incluem mudanças na dieta (preferência por alimentos moles), bem como modificações no estilo de vida em geral, uso de relaxantes musculares, aparelhos oclusais e fisioterapia (Renapurkar, 2018). 
Por conseguinte, terapia física local, reabilitação, exercícios, redução dos fatores mecânicos sobre a articulação e ainda terapias alternativas podem proporcionar a pessoa acometida melhorias e manutenção da função articular, o que reflete principalmente no ganho de qualidade de vida dessas pessoas. A fisioterapia também está entre uma das formas de terapia física de tratamento para a osteoartrose e, quando bem indicada, oferece excelentes respostas. Mas de qualquer forma, um profissional preparado e com conhecimento sobre as atuais alternativas terapêuticas é indispensável para que bons resultados sejam alcançados e para que orientações sejam feitas de maneira específica e individualizada para cada paciente (Duarte et al., 2013).

\subsubsection{Osteoartrite}

A osteoartrite é entendida como um defeito articular resultante de processos complexos de doenças interativas em diferentes estruturas articulares e periarticulares, incluindo a cartilagem, membrana sinovial, músculos, osso subcondral e cortical (Lange-Brokaar et al., 2012). Os seus estágios iniciais de desenvolvimento são, na maioria, subclínicos, impedindo o diagnóstico preciso tanto clínico quanto radiográfico (Costa et al., 2020).

Na maioria dos casos de osteoartrite da ATM, a etiologia é complexa e multifatorial ou desconhecida (Wang et al., 2015). Embora a patogênese dessa condição não seja completamente clara, descobertas têm sugerido que o acúmulo de vários fatores inflamatórios desencadeia a falha no equilíbrio metabólico dos condrócitos (Miettinen et al., 2017). Além disso, outros fatores como assimetria e estresse excessivo podem ser transmitidos ao tecido ósseo subcondral da ATM, levando o osso à reabsorção e eventualmente, evoluindo para o quadro de osteoartrite (Wang et al., 2015).

Os termos osteoartrite e osteoartrose são subclasses das doenças degenerativas, implicando na presença e ausência de dor, respectivamente (Schiffman et al., 2014). Dessa maneira, apesar de apresentar semelhança à osteoartrose em variados âmbitos, a osteoartrite distingue-se consideravelmente pela presença de inflamação da ATM (Neto et al., 2013), que se mostra como uma sequela secundária ao remodelamento ósseo não estabelecido das superfícies ósseas submetidas à sobrecarga (Dawson, 2008).

O sintoma mais frequente da osteoartrite da ATM é a dor no decorrer da mastigação. A sensação dolorosa geralmente tem início no tecido mole periarticular e nos músculos mastigatórios que estão em espasmo - reflexo protetor. Outros indicativos que também fazem parte da caracterização desse distúrbio são: redução da amplitude de movimento, dificuldade em abertura bucal, crepitações nas articulações, trismo e fadiga dos músculos da mastigação (Bag et al., 2014; Liu et al., 2019). Geralmente, pacientes com osteoartrite possuem longos desvios da posição de relação cêntrica (RC) para a posição de máxima intercuspidação habitual (MIH), sobressaliência aumentada e tendência à mordida aberta anterior, com risco aumentado para essas desordens estando predominantemente associado às variações extremas dessas condições (Costa et al., 2020).

No que se refere ao processo de diagnóstico, a avaliação clínica da ATM pode ser aprimorada realizando um leve toque no canal auditivo e palpando a parede do canal anterior enquanto o paciente abre e fecha a boca. A crepitação neste local está relacionada à ruptura da superfície articular e pode sugerir o diagnóstico de osteoartrite. $\mathrm{O}$ uso de um estetoscópio pode ser um complemento útil para confirmar a presença de crepitação na ATM (Cavalcante et al., 2020). Todavia, embora a crepitação detectada à palpação seja sugestiva de doença degenerativa, o diagnóstico deve ser confirmado por imagem (Schiffman et al., 2014).

Sendo assim, a osteoartrite da ATM é um subtipo importante de desordens temporomandibulares, que são diagnosticadas não só com base nos sintomas clínicos, mas com análises de imagens da cartilagem condilar ou osso subcondral. As características radiográficas encontradas em casos de osteoartrite da ATM são: irregularidade óssea cortical da superfície articular, erosão e formação de osteófitos que ocorre mais tipicamente em um estágio avançado da doença, podendo 
estabilizar e ampliar a área de superfície da articulação na tentativa de melhor suportar as forças de carga axial (Liu et al., 2019).

No que se refere ao tratamento, todas as abordagens buscam, sobretudo, o alívio da dor, como também desacelerar o progresso da doença e restaurar a função da ATM (Wang et al., 2015) a fim de devolver um quadro de normalidade para os indivíduos acometidos, principalmente, de remodelação tecidual e adaptação assintomática à degeneração (Costa et al., 2020). Nesse âmbito, a farmacoterapia mostra-se necessária, uma vez que analgésicos ou anti-inflamatórios não esteroides podem ser prescritos para o controle da dor e inflamação articular. E, para paciente com hiperatividade muscular são recomendados relaxantes musculares ou agentes ansiolíticos. Por outro lado, o uso de placa estabilizadora durante o maior tempo possível é indicado devido à sobrecarga mecânica da articulação ser a principal causa da osteoartrite (Neto et al., 2013; Wang et al., 2015). A artrocentece com lubrificação ou corticosteroide também se apresenta como uma opção não cirúrgica viável para o tratamento convencional desse distúrbio (Wang et al., 2015).

Em contrapartida, alguns medicamentos vêm sendo administrados por injeção intra-articular para pacientes com osteoartrite da ATM que incluem a toxina botulínica A, plasma rico em plaquetas (PRP) e fatores de crescimento derivados de plaquetas (PDGF) (Fernández et al., 2016).

Lora et al. (2017) investigaram os efeitos antinociceptivos da injeção intra-articular de toxina botulínica A na hipernocicepção inflamatória persistente induzida por artrite na ATM de ratos e como resultado, constatou-se que devido à diminuição significativa da liberação periférica de neuropeptídeos essa toxina reduziu a hipernocicepção inflamatória persistente induzida por artrite na ATM desses animais. Todavia, os ensaios clínicos estão em andamento e são necessários para investigar seu efeito curativo em pacientes acometidos por essa doença articular degenerativa.

O PRP usado para tratar a osteoartrite da ATM e considerado como um método promissor por seu excelente efeito curativo e relativa segurança. $\mathrm{O}$ efeito à longo prazo do plasma intra-articular rico em plaquetas foi superior ao hialuronato de sódio na melhora da dor e da abertura da boca (Hegab et al., 2015; Zotti et al., 2019).

De outra forma, a cirurgia deve ser indicada quando a degeneração articular resulta em má oclusão, deformidade dentofacial, dor incessante e perda de função. Assim, as intervenções cirúrgicas comuns incluem recontorno ósseo, reparo ou remoção de disco, condilotomia, cirurgia ortognática e reconstrução aloplástica da articulação total (Renapurkar, 2018).

\subsection{Anquilose}

\subsubsection{Anquilose fibrosa}

A anquilose da ATM é um distúrbio pelo qual a adesão dos componentes da articulação efetua-se através de uma união fibrosa ou óssea, ocasionando perda de função e movimento (Ahmad e Schiffman, 2016). Desse modo, tal condição é profundamente deformante e incapacitante e a gravidade da deformidade é baseada no início, duração e o tipo da anquilose. Dependendo do tipo de tecido envolvido, a anquilose da ATM classifica-se em fibrosa, óssea ou fibro-óssea, podendo ser unilateral ou bilateral (Khanna e Ramaswami, 2019), como também pode ser classificada de acordo com sua localização em intra ou extracapsular (Ahmad e Schiffman, 2016).

A fisiopatologia da anquilose da ATM é explicada por uma progressão contínua das aderências articulares que gradualmente criam uma limitação significativa do movimento articular. A inflamação agrava o distúrbio, uma vez que resulta no aparecimento de tecido mais fibroso. Situações que causam traumatismo, onde há deslocamento ou fratura condilar com rompimento periosteal e consequentemente hemorragia, produzem a formação de coágulos, que podem conduzir a união óssea da superfície côndilo articular ao osso temporal. As características clínicas podem variar conforme o tempo de evolução, a idade em que o processo foi iniciado e se a alteração é unilateral ou bilateral (Molina et al., 2013). 
A anquilose fibrosa é mais comum e fatores como trauma na região anterior do mento, com compressão severa no sentido posterior do côndilo, hemartrose, infecções otológicas recorrentes, como a otite média aguda estão intimamente ligados a sua etiologia (Neto et al., 2013). No quadro clínico desse tipo de anquilose, evidencia-se uma abertura interincisal bastante limitada da boca (Tamimi et al., 2018) com deflexão para o lado afetado na abertura, mas caso o comprometimento seja bilateral, as assimetrias nos movimentos mandibulares durante o exame clínico serão menos pronunciadas ou inexistentes (Peck et al., 2014).

Segundo Rajurkar et al. (2017), a significativa redução na abertura bucal manifesta-se, principalmente, no comprometimento da fala, dificuldade na mastigação, deformidade facial e características associadas: pobre higiene bucal e doença periodontal, distúrbios oclusais e de crescimento envolvendo maxila e mandíbula, dificuldade de respirar, e via aérea comprometida caracterizada por apneia do sono.

No que se refere ao diagnóstico, a ressonância magnética é um método capaz de determinar a presença de tecido ósseo, anquilose fibrosa e fibro-óssea, sendo, portanto, decisiva nesse processo de detecção (Molina et al., 2013). Dessa maneira, radiograficamente, é possível verificar que o espaço articular é frequentemente restrito e ainda, as superfícies condilares e da fossa podem ser irregulares (Peck et al., 2014).

Em virtude de se tratar de uma doença degenerativa em estágio avançado, a intervenção cirúrgica é recomendada seguida de intensa fisioterapia. Sendo assim, o tratamento cirúrgico da anquilose possui diversas técnicas de realização que variam conforme a severidade e o tipo apresentados. Algumas abordagens terapêuticas incluem artroplastia simples, artroplastia interposicional, ressecção do bloco anquilótico e reconstrução com enxerto ósseo (Neto et al., 2013). As complicações mais frequentemente relatadas após o tratamento da anquilose são limitação da abertura da boca e reanquilose, que pode ocorrer dentro de um período de seis meses no pós-operatório. Essa reanquilose pode ser prevenida pela ressecção agressiva dos tecidos ósseos ou fibrosos, especialmente no aspecto medial do côndilo, e pela colocação de materiais interposicionais (Anyanechi et al., 2015).

Para Hu et al. (2017), o tratamento da anquilose da ATM é muito complexo, pois a recorrência ainda é um fenômeno bastante comum em grande parte dos casos descritos pela literatura. Dessa forma, o conhecimento profissional é elemento fundamental na classificação da anquilose da ATM e para a escolha do método de tratamento ideal para cada caso.

\subsubsection{Anquilose óssea}

A anquilose óssea é um distúrbio resultante da união dos ossos da ATM através da proliferação de células ósseas, o que pode ocasionar a absoluta imobilidade dessa articulação (Peck et al., 2014). Essa condição é mais usualmente relacionada a infecção prévia, casos de fratura condilar com histórico de complicação e inflamação crônica. E, os sinais clínicos são bastante similares aos encontrados na anquilose fibrosa (Neto et al., 2013).

Em relação à etiologia, as principais são: trauma, infecção e a hemartrose. Esta última é definida como a existência secundária de sangue dentro da articulação. O sangue, normalmente, é resultante de um macrotrauma craniofacial, principalmente na região mandibular e do mento. Outras causas para a anquilose óssea incluem doenças sistêmicas como a artrite reumatóide, espondilite anquilosante, miosite ossificante, doenças infecciosas como sarampo ou fibrodisplasia ossificante progressiva. Além disso, há também atribuições como as complicações pós-operatórias e infecções locais, tais como infecções do processo alveolar dentário, ouvido médio ou mastoide, entre outras (Akshat et al., 2017; Molina et al., 2013).

Para realização do diagnóstico, a tomografia computadorizada ou a tomografia computadorizada de feixe-cônico são os principais exames utilizados. Nesse contexto, a anquilose óssea se caracteriza, radiograficamente, pela proliferação óssea 
com acentuada deflexão no lado afetado e intensa extrusão posterior no lado contralateral (Peck et al., 2014). Além disso, essa técnica de imagem pode ser necessária ainda para o planejamento cirúrgico (Bag et al., 2014).

Após o estabelecimento do diagnóstico de anquilose da ATM, o tratamento fundamenta-se na priorização do procedimento cirúrgico, de maneira mais precoce possível, com o intuito de remover o bloco ósseo e simultaneamente, preservar a altura do ramo mandibular e prevenir a recidiva com materiais de interposição (Rajurkar et al., 2017).

O tratamento desse distúrbio articular apresenta diferentes modalidades de execução como a artroplastia de gap, artroplastia interposicional, prótese articular e distração osteogênica, dentre outros (Rajurkar et al., 2017). Alguns cirurgiões recomendam que a artroplastia e distração osteogênica sejam realizadas durante a mesma fase, a fim de melhorar a restrição na abertura da boca e deformidade maxilofacial simultaneamente, evitando assim uma segunda cirurgia (Zhang et al., 2018). Entretanto, além de apresentar uma alta taxa de recorrência, o tratamento de anquilose da ATM é associado a muitas complicações que representam um significativo desafio para o clínico (Rajurkar et al., 2017).

Zhang et al. (2018) avaliaram o tratamento sequencial de pacientes com anquilose da ATM e deformidades secundárias por distração osteogênica e posterior artroplastia ou reconstrução da articulação. Este estudo incluiu 40 pacientes com idade entre 9 e 53 anos, onde 10 deles foram diagnosticados com anquilose unilateral e 30 com anquilose bilateral da ATM. Além disso, 27 pacientes apresentavam também síndrome da apneia-hipopneia obstrutiva do sono (SAHOS). Por conseguinte, todas as pessoas do estudo foram submetidas à distração osteogênica como cirurgia inicial, seguida de artroplastia ou reconstrução da ATM. Alguns pacientes foram submetidos à cirurgia ortognática para melhorar a oclusão e o formato do rosto junto com ou após a artroplastia ou reconstrução da ATM. Os efeitos terapêuticos foram avaliados em termos de melhorias na abertura interincisal máxima (AIM), aparência e função respiratória. Após o término do tratamento, todos os pacientes apresentaram melhora na AIM e na aparência, e o sintoma de ronco desapareceu. O espaço das vias aéreas foi significativamente aumentado. O acompanhamento dos pacientes variou de 6 a 85 meses (média de 28,3 meses) e apenas quatro deles tiveram recaída. Em suma, esse estudo sugere que o tratamento da anquilose da ATM com deformidades secundárias por distração osteogênica como cirurgia inicial e artroplastia ou reconstrução da ATM como tratamento de segundo estágio pode alcançar resultados favoráveis. Todavia, alguns pacientes podem precisar de cirurgia ortognática.

É válido ressaltar que em casos de anquilose fibrosa ou óssea, a fisioterapia é um recurso essencial na recuperação de pacientes reabilitados cirurgicamente, uma vez que o reaparecimento de tecido fibroso na área operada é alto. Desse modo, são preconizados exercícios simples que, uma vez iniciados no ambiente ambulatorial, são naturalmente reproduzíveis pelo paciente. Na fase inicial da terapia, os exercícios de abertura levemente forçada, associados à contrarresistência são os mais apropriados (Neto et al., 2013).

\section{Considerações Finais}

Com base na literatura pesquisada, foi possível constatar que os distúrbios intracapsulares da ATM estão associados, muitas vezes, a uma etiologia multifatorial e apesar disso, podem apresentar sinais e sintomas clínicos muito semelhantes entre si, à exemplo dor orofacial de intensidade variável, limitação dos movimentos mandibulares e sons articulares. Por conseguinte, algumas DTMs podem passar despercebidas durante o exame clínico pelo quadro assintomático do paciente.

Tendo em vista que os pacientes acometidos por tais condições buscam inicialmente o atendimento odontológico, se faz necessário que os cirurgiões-dentistas e futuros profissionais tenham compreensão e conhecimento adequados acerca dessa temática para que possam realizar o diagnóstico precoce e planejar condutas de tratamento condizentes à necessidade do paciente, visando um melhor prognóstico. Nesse âmbito, evidenciou-se que os exames de imagem, como radiografias 
panorâmicas, ressonância magnética e tomografia computadorizada são métodos que fornecem um suporte complementar indispensável para o correto diagnóstico dos distúrbios que afetam a ATM.

Portanto, entende-se que o papel do cirurgião-dentista no atendimento primário do paciente com algum tipo de DTM é imprescindível para o melhor desempenho do tratamento, refletindo, sobretudo, na redução das cronificações da doença, visto que o diagnóstico precoce e o início de um tratamento que induza a adaptação da articulação frente às desordens são fatores substanciais para impedir a evolução para quadros clínicos mais severos, à exemplo, de doenças degenerativas. Adicionalmente, foi possível corroborar a existência de amplas modalidades de tratamento para os distúrbios intracapsulares da ATM, com abordagens tanto conservadoras quanto cirúrgicas e que dependendo da necessidade de intervenção e gravidade de cada caso clínico, cabe ao profissional direcionar a melhor conduta para o paciente. Ademais, sugere-se para trabalhos futuros que sejam pesquisados o desenvolvimento de novas alternativas no tratamento da DTM, bem como métodos mais atuais para um diagnóstico mais rápido e preciso.

\section{Referências}

Abbehusen, C. (2019). Ressonância magnética na avaliação do desarranjo articular interno da articulação temporomandibular. Revista Científica HSI, 3(3), $158-163$.

Ahmad, M., \& Schiffman, E. L. (2016). Temporomandibular Joint Disorders and Orofacial Pain. Dental clinics of North America, 60(1), $105-124$.

Aiken, A., Bouloux, G., \& Hudgins, P. (2012). MR imaging of the temporomandibular joint. Magnetic resonance imaging clinics of North America, 20(3), $397-412$.

Aires, C., Peixoto, L., Lima, I., Silva, C., \& Vasconcellos, R. (2020). Atualizações e avanços na etiopatogenia e tratamento dos tumores da articulação temporomandibular. Research, Society and Development, 9(10), e7139109104. 2020.

Akinbami, B. O. (2011). Evaluation of the mechanism and principles of management of temporomandibular joint dislocation. Systematic review of literature and a proposed new classification of temporomandibular joint dislocation. Head \& Face Medicine, 7(1), 7-10.

Akshat, S., Jain, S., Khanna, P., \& Batra, R. K. (2017). Airway management of a paediatric patient with temporomandibular joint ankylosis with extra hepatic portal vein obstruction, splenomegaly, hypersplenism, and obstructive sleep apnoea for shunt surgery: A unique challenge. Indian journal of anaesthesia, 61(11), 943-944.

Alomar, X., Medrano, J., Cabratosa, J., Clavero, J. A., Lorente, M., Serra, I., Monill, J. M., \& Salvador, A. (2007). Anatomy of the temporomandibular joint. Seminars in ultrasound, CT, and MR, 28(3), 170-183.

Anyanechi, C., Osunde, O., \& Bassey, G. (2015). Use of oral mucoperiosteal and pterygo-masseteric muscle flaps as interposition material in surgery of temporomandibular joint ankylosis: a comparative study. Annals of medical and health sciences research, 5(1), 30-35.

Bag, A. K., Gaddikeri, S., Singhal, A., Hardin, S., Tran, B. D., Medina, J. A., \& Curé, J. K. (2014). Imaging of the temporomandibular joint: An update. World journal of radiology, 6(8), 567-582.

Bas, B., Yuceer, E., Kazan, D., Gurbanov, V., \& Kutuk, N. (2019). Clinical and intra-operative factors affecting the outcome of arthrocentesis in disc displacement without reduction: A retrospective study. Journal of oral rehabilitation, 46(8), 699-703.

Bavaresco, C., Grossmann, T., Rehm, D., \& Grossmann, E. (2020). Effect of mesenchymal stem cells on the regeneration of structures associated with temporomandibular joint: narrative review. Brazilian Journal Of Pain, 3(3), 275-279.

Berenbaum, F. (2013). Osteoarthritis as an inflammatory disease (osteoarthritis is not osteoarthrosis!). Osteoarthritis And Cartilage, $21(1)$, 16-21.

Bonotto, D., Machado, E., Cunali, R., \& Cunali, A. (2014). Viscosupplementation as a treatment of internal derangements of the temporomandibular joint: retrospective study. Revista Dor, 15(1), 2-5.

Breton-torres, I., Trichot, S., Jacques, Y., \& Jammet, P. (2016). Dysfonction de l'appareil manducateur: approches rééducative et posturale. Revue de Stomatologie, de Chirurgie Maxillo-Faciale Et de Chirurgie Orale, 117(4), 217-222.

Callhoff, J., Sieper, J., Weiß, A., Zink, A., Listing, J. (2015). Efficacy of TNF $\alpha$ blockers in patients with ankylosing spondylitis and non-radiographic axial spondyloarthritis: a meta-analysis. Ann Rheum Dis, 74(6), 1241-8.

Calis, A., Colakoglu, Z., Gunbay, S. (2019). The use of botulinum toxin-a in the treatment of muscular temporomandibular joint disorders. J Stomatol Oral Maxillofac Surg, 120(4), 322-325.

Cavalcante, S., Linhares, N., Couto, M., Santiago, T., Lima, K., Pinto, A., Bezerra, Y., Mendes, T., Dinelly, E. (2020). Abordagem terapêutica multidisciplinar para o tratamento de dores orofaciais: uma revisão de literatura. Brazilian Journal Of Development, 6(7), 44293-44310. 
Chandrashekhar, V. K. (2015). Arthrocentesis A Minimally Invasive Method for T MJ Disc Disorders - A Prospective Study. Journal Of Clinical And Diagnostic Research, 9(10), ZC59-ZC62.

Connor, R. C., Fawthrop, F., Salha, R., \& Sidebottom, A. J. (2017). Management of the temporomandibular joint in inflammatory arthritis: Involvement of surgical procedures. European journal of rheumatology, 4(2), 151-156.

Costa, I. C. da S., Detoni, J. C., Galvão, S. A., Lucietto, G., Santos, E. B. dos ., Fosquiera , E. C. ., Nabhan , A. L. R. ., Sabec, G. Z. ., Araújo, C. de S. A., \& Boleta-Ceranto, D. de C. F. (2020). Prevalence of osteoarthritis in patients at a dental school clinic and its relationship with DTM. Research, Society and Development, 9(11), e70591110160.

Costa, M. R., de Melo Christofolleti, L. Z., Nóbrega Barbosa, K. G., Figueiredo Nóbrega, D., Lima Nobre Pinheiro, M., \& Cavalcante, M. K. (2019). Disfunção temporomandibular, sintomas otológicos e sua associação com achados de imagem de ressonância magnética. Diversitas Journal, 4(2), 622-630.

Dalewski, B., Kamińska, A., Szydłowski, M., Kozak, M., \& Sobolewska, E. (2019). Comparison of Early Effectiveness of Three Different Intervention Methods in Patients with Chronic Orofacial Pain: A Randomized, Controlled Clinical Trial. Pain research \& management, 7954291.

Dantas, L, Tenório, M., Lins, G., Figueiredo Filho, A., Duarte, L., Santana, B., Rocha, N. (2019). A evolução do tratamento das desordens temporomandibulares. Brazilian Journal of Surgery and Clinical Research, 27(3), 108-113.

Dawson, P. E. (2008). Oclusão Funcional: Da ATM ao Desenho do Sorriso. 1. ed. São Paulo: Santos Editora.

de Brito Silva, L. N., dos Santos, E. G. F., Ávilla, E. C., Moreira, L. G. C., da Silva, M. C., de Almeida, I. T., \& de Souza Andrade, E. S. (2020). A presença da disciplina de dor orofacial e disfunção temporomandibular nas faculdades de odontologia do nordeste brasileiro. Research, Society and Development, 9(10), e6419109049-e6419109049.

de la Torre Molina, Y., \& Cabrera Velázquez, M. (2018). Desajustes intra-articulares no paciente geriátrico. Espirituana Medical Gazette, 20 (2), 69-82.

DeMerle, M., Nafiu, O. O., \& Aronovich, S. (2017). Temporomandibular Joint Discectomy With Abdominal Fat Graft Versus Temporalis Myofascial Flap: A Comparative Study. Journal of oral and maxillofacial surgery: official journal of the American Association of Oral and Maxillofacial Surgeons, 75(6), 1137-1143.

De Rossi, S. S., Greenberg, M. S., Liu, F., \& Steinkeler, A. (2014). Temporomandibular disorders: evaluation and management. The Medical clinics of NorthAmerica, 98(6), 1353-1384.

Dias, I. M., Cordeiro, P. C., Devito, K. L., Tavares, M. L., Leite, I. C., \& Tesch, R. (2016). Evaluation of temporomandibular joint disc displacement as a risk factor for osteoarthrosis. International journal of oral and maxillofacial surgery, 45(3), 313-317.

Dimitroulis, G. (2011). A critical review of interpositional grafts following temporomandibular joint discectomy with an overview of the dermis-fat graft. International Journal Of Oral And Maxillofacial Surgery, 40(6), 561-568.

Dimitroulis, G., Mccullough, M., Morrison, W. (2010). Quality-of-Life Survey Comparing Patients Before and After Discectomy of the Temporomandibular Joint. Journal Of Oral And Maxillofacial Surgery, 68(1), 101-106.

Duarte, V., Santos, M., Rodrigues, K., Ramires, J., Arêas, G., \& Borges, G. (2013). Exercícios físicos e osteoartrose: uma revisão sistemática. Fisioterapia em Movimento, 26(1), 193-202.

Fernández Sanromán, J., Fernández Ferro, M., Costas López, A., Arenaz Bua, J., \& López, A. (2016). Does injection of plasma rich in growth factors after temporomandibular joint arthroscopy improve outcomes in patients with Wilkes stage IV internal derangement? A randomized prospective clinical study. International journal of oral and maxillofacial surgery, 45(7), 828-835.

Ferri, J., Potier, J., Maes, J. M., Rakotomalala, H., Lauwers, L., Cotelle, M., \& Nicot, R. (2018). Temporomandibular joint arthritis: Clinical, orthodontic, orthopaedic and surgical approaches. International orthodontics, 16(3), 545-561.

Galvão, C. S. et al. (2020). Avaliação funcional após terapias de placa oclusal e fisioterapia em pacientes com DTM: ensaio clínico randomizado. Research, Society and Development, 9(11), e1309119688.

Gauer, R. L., \& Semidey, M. J. (2015). Diagnosis and treatment of temporomandibular disorders. American family physician, 91(6), 378-386.

Gil-Martínez, A., Paris-Alemany, A., López-de-Uralde-Villanueva, I., \& La Touche, R. (2018). Management of pain in patients with temporomandibular disorder (TMD): challenges and solutions. Journal of pain research, 11, 571-587.

Giraudeau, A., Jeany, M., Ehrmann, E., Déjou, J., Ouni, I., \& Orthlieb, J. D. (2017). Disc displacement without re duction: a retrospective study of a clinical diagnostic sign. Cranio: the journal of craniomandibular practice, 35(2), 86-93.

Goiato, M. C., da Silva, E. V., de Medeiros, R. A., Túrcio, K. H., \& Dos Santos, D. M. (2016). Are intra-articular injections of hyaluronic acid effective for the treatment of temporomandibular disorders? A systematic review. International journal of oral and maxillofacial surgery, 45(12), $1531-1537$.

Gupta, N., Gupta, N., Tomar, L. R., \& Nair, N. (2016). Temporomandibular joint ankylosis in ankylosing spondylitis: A case report and review of literature. Journal of family medicine and primary care, 5(3), 716-718.

Hamza, A., Gidley, P. W., Learned, K. O., Hanna, E. Y., \& Bell, D. (2020). Uncommon tumors of temporomandibular joint: An institutional experience and review. Head \& neck, 42(8), 1859-1873.

Hegab, A. F., Ali, H. E., Elmasry, M., \& Khallaf, M. G. (2015). Platelet-Rich Plasma Injection as an Effective Treatment for Temporomandibular Joint Osteoarthritis. Journal of oral and maxillofacial surgery: official journal of the American Association of Oral and Maxillofacial Surgeons, 73(9), 1706-1713. 
Hillam, J., Isom, B. (2020). Mandible dislocation. StatePearls Publishing.

Hu, Y., Zhang, L., He, D., Yang, C., Chen, M., Zhang, S., Li, H., \& Ellis, E., III (2017). Simultaneous treatment of temporomandibular joint ankylosis with severe mandibular deficiency by standard TMJ prosthesis. Scientific reports, 7, 45271.

Hussain, A. M., Packota, G., Major, P. W., \& Flores-Mir, C. (2008). Role of different imaging modalities in assessment of temporomandibular joint erosions and osteophytes: a systematic review. Dento maxillo facial radiology, 37(2), 63-71.

Ibi, M. (2019). Inflammation and Temporomandibular Joint Derangement. Biological And Pharmaceutical Bulletin, 42(4), 538-542.

Ifteni, G., Apostu, A., Tanculescu, O. (2016). Dental occlusion and the importance of its proper investigation - Part I. Romanian Journal of Oral Rehabilitation, 8(2), 94-100.

Ikeda, K., Kawamura, A. (2013). Disc displacement and changes in condylar position. Dentomaxillofacial Radiology, 42(3).

Israel, H. A. (2016). Internal derangement of temporomandibular joint: new perspectives on an old problem. Oral Maxillofac Surg Clin North Am., 28(3), 313333.

Jordani, P. C., Campi, L. B., Braido, G., Fernandes, G., Visscher, C. M., \& Gonçalves, D. (2019). Obesity, sedentarism and TMD-pain in adolescents. Journal of oral rehabilitation, 46(5), 460-467.

Junior, R., Manzi, M., Carvalho, M., Luz, J., Pimentel, A., \& Deboni, M.. (2015). Manual reduction of articular disc after traumatic extraction of mandibular third molar: a case report. Dental Press Journal of Orthodontics, 20(5), 101-107.

Katzberg, R. W., Tallents, R. H. (2005). Normal and Abnormal Temporomandibular Joint Disc and Posterior Attachment as Depicted by Magnetic Resonance Imaging in Symptomatic and Asymptomatic Subjects. Journal Of Oral And Maxillofacial Surgery, 63(8), $1155-1161$.

Khalighi, H. R., Mortazavi, H., Mojahedi, S. M., Azari-Marhabi, S., \& Moradi Abbasabadi, F. (2016). Low Level Laser Therapy Versus Pharmacotherapy in Improving Myofascial Pain Disorder Syndrome. Journal of lasers in medical sciences, 7(1), 45-50.

Khanna, J.N., Ramaswami, R. (2019). Protocol for the management of ankylosis of the temporomandibular joint. The British Association of Oral and Maxillofacial Surgeons, 57(10), 1113-1118.

Khiavi, H., Ebrahimi, H., Najafi, S., Nakisa, M., Habibzadeh, S., Khayamzadeh, M., \& Kharazifard, M. J. (2020). Efficacy of Low-Level Laser, Hard Occlusal Appliance and Conventional Pharmacotherapy in the Management of Myofascial Pain Dysfunction Syndrome; A Preliminary Study. Journal of lasers in medical sciences, 11(1), 37-44.

Kim, J. Y., Jeon, K. J., Kim, M. G., Park, K. H., \& Huh, J. K. (2018). A nomogram for classification of temporomandibular joint disk perforation based on magnetic resonance imaging. Oral surgery, oral medicine, oral pathology and oral radiology, 125(6), 682-692.

Korkmaz, Y. T., Altıntas, N. Y., Korkmaz, F. M., Candırlı, C., Coskun, U., \& Durmuslar, M. C. (2016). Is Hyaluronic Acid Injection Effective for the Treatment of Temporomandibular Joint Disc Displacement With Reduction?. Journal of oral and maxillofacial surgery: official journal of the American Association of Oral and Maxillofacial Surgeons, 74(9), 1728-1740.

Krasnokutsky, S., Attur, M., Palmer, G., Samuels, J., \& Abramson, S. B. (2008). Current concepts in the pathogenesis of osteoarthritis. Osteoarthritis and cartilage, 16 Suppl 3, S1-S3.

Kroese, J., Volgenant, C., Schaardenburg, D., Loos, B., Crielaard, W., \& Lobbezoo, F. (2020). Temporomandibular joint function, periodontal health and oral microbiome in individuals with initial and at-risk rheumatoid arthritis: a prospective cohort study protocol. BDJ Open, 6(1), 1-5.

Kumar, R., Pallagatti, S., Sheikh, S., Mittal, A., Gupta, D., \& Gupta, S. (2015). Correlation Between Clinical Findings of Temporomandibular Disorders and MRI Characteristics of Disc Displacement. The open dentistry journal, 9, 273-281.

La Touche, R., Boo-Mallo, T., Zarzosa-Rodríguez, J., Paris-Alemany, A., Cuenca-Martínez, F., \& Suso-Martí, L. (2020). Manual therapy and exercise in temporomandibular joint disc displacement without reduction. A systematic review. Cranio: the journal of craniomandibular practice, $1-11$.

Lange-Brokaar, B. J., Ioan-Facsinay, A., van Osch, G. J., Zuurmond, A. M., Schoones, J., Toes, R. E., Huizinga, T. W., \& Kloppenburg, M. (2012). Synovia1 inflammation, immune cells and their cytokines in osteoarthritis: a review. Osteoarthritis and cartilage, 20(12), 1484-1499.

Lee, S., Yoon, H. (2009). The relationship between MRI findings and the relative signal intensity of retrodiscal tissue in patients with temporomandibular joint disorders. Oral Surgery, Oral Medicine, Oral Pathology, Oral Radiology, And Endodontology, 107 (1), 113-115.

Leeuw, R. de. (2008). Internal Derangements of the Temporomandibular Joint. Oral And Maxillofacial Surgery Clinics Of North America, 20 (2), $159-168$.

Li, W., Cheng, Y., Wei, L., Li, B., \& Zheng, H. (2019). Gender and Age Differences of Temporomandibular Joint Disc Perforation: A Cross-Sectional Study in a Population of Patients With Temporomandibular Disorders. The Journal of craniofacial surgery, 30(5), 1497-1498.

Liddell, A., Perez, D. E. (2015). Temporomandibular Joint Dislocation. Oral And Maxillofacial Surgery Clinics Of North America, 27 (1), $125-136$.

Lima, A. I. S. (2019). DTM articular, seu diagnóstico e tratamento: relato de caso. FACSETE.

Lima, L., Silva, F., Monteiro, M., Junior, G. (2020). Depressão e ansiedade e a associação com disfunções temporomandibulares - revisão de literatura. Research, Society and Development, 9(7), e579974540. 
Lin, W. C., Lo, C. P., Chiang, I. C., Hsu, C. C., Hsu, W. L., Liu, D. W., Juan, Y. H., \& Liu, G. C. (2012). The use of pseudo-dynamic magnetic resonance imaging for evaluating the relationship between temporomandibular joint anterior disc displacement and joint pain. International journal of oral and maxillofacial surgery, 41(12), 1501-1504.

Litko, M., Berger, M., Szkutnik, J., \& Różyło-Kalinowska, I. (2017). Correlation between direction and severity of temporomandibular joint disc displacement and reduction ability during mouth opening. Journal of oral rehabilitation, 44(12), 957-963.

Liu, F., Steinkeler, A. (2013). Epidemiology, Diagnosis, and Treatment of Temporomandibular Disorders. Dental Clinics Of North America, 57(3), 465-479.

Liu, Y., Wu, J. S., Tang, Y. L., Tang, Y. J., Fei, W., \& Liang, X. H. (2020). Multiple Treatment Meta-Analysis of Intra-Articular Injection for Temporomandibular Osteoarthritis. Journal of oral and maxillofacial surgery: official journal of the American Association of Oral and Maxillofacial Surgeons, 78(3), 373.e1-373.e18.

Liu, X. M., Zhang, S. Y., Yang, C., Chen, M. J., Y Cai, X., Haddad, M. S., Yun, B., \& Chen, Z. Z. (2010). Correlation between disc displacements and locations of disc perforation in the temporomandibular joint. Dento maxillo facial radiology, 39(3), 149-156.

Lora, V. R., Clemente-Napimoga, J. T., Abdalla, H. B., Macedo, C. G., Canales, G. T., \& Barbosa, C. M. (2017). Botulinum toxin type A reduces inflammatory hypernociception induced by arthritis in the temporomadibular joint of rats. Toxicon: official journal of the International Society on Toxinology, 129, 52-57.

Machoň, V., Vir, J., Levorová, J., Beňo, M., Hirjak, D., \& Foltán, R. (2020). Discectomy with Subsequent Free Fat Flap Insertion in Disc Perforation Therapy of Temporomandibular Joint. Assessment of Results 24 Months after Operation. Prague medical report, 121(2), 96-106.

Machon, V., Levorova, J., Hirjak, D., Drahos, M., \& Foltan, R. (2017). Temporomandibular joint disc perforation: a retrospective study. International journal of oral and maxillofacial surgery, 46(11), 1411-1416.

Malachovsky, I., Statelova, D., Stasko, J., Mikuskova, K., Smatanova, M., \& Janickova, M. (2019). Therapeutic effects of arthrocentes is in treatment of temporomandibular joint disorders. Bratislavske lekarske listy, 120(3), 235-239.

Malmström, V., Catrina, A. I., \& Klareskog, L. (2017). The immunopathogenesis of seropositive rheumatoid arthritis: from triggering to targeting. Nature reviews. Immunology, 17(1), 60-75.

Marqués-Mateo, M., Puche-Torres, M., \& Iglesias-Gimilio, M. E. (2016). Temporomandibular chronic dislocation: The long-standing condition. Medicina oral, patologia oral y cirugia bucal, 21(6), e776-e783.

Medra, A. M., \& Mahrous, A. M. (2008). Glenotemporal osteotomy and bone grafting in the management of chronic recurrent dislocation and hypermobility of the temporomandibular joint. The British journal of oral \& maxillofacial surgery, 46(2), 119-122.

Melo, A. R., Pereira Júnior, E. D., Santos, L., \& Vasconcelos, B. (2017). Recurrent dislocation: scientific evidence and management following a systematic review. International journal of oral and maxillofacial surgery, 46(7), 851-856.

Mendes, A. G. (2012). Abordagem terapêutica da patologia inflamatória da articulação temporomandibular (Doctoral dissertation, [sn]).

Miettinen, O., Anttonen, V., Patinen, P., Päkkilä, J., Tjäderhane, L., \& Sipilä, K. (2017). Prevalence of Temporomandibular Disorder Symptoms and Their Association with Alcohol and Smoking Habits. Journal of oral \& facial pain and headache, 31(31), 30-36.

Miloro, M., \& Henriksen, B. (2010). Discectomy as the primary surgical option for internal derangement of the temporomandibular joint. Journal of oral and maxillofacial surgery: official journal of the American Association of Oral and Maxillofacial Surgeons, 68(4), 782-789.

Molina, D., Aguayo, P., Ulloa, C., Iturriaga, V., Bornhardt, T., \& Saavedra, M. (2013). Anquilose da articulação temporomandibular: uma revisão da literatura. Advances in odontostomatology, 29 (5), 239-244.

Muñoz-Guerra, M. F., Rodríguez-Campo, F. J., Escorial Hernández, V., Sánchez-Acedo, C., \& Gil-Díez Usandizaga, J. L. (2013). Temporomandibular joint disc perforation: long-term results after operative arthroscopy. Journal of oral and maxillofacial surgery: official journal of the American Association of Oral and Maxillofacial Surgeons, 71(4), 667-676.

Neto, A. J. F.; Neves, F. D. Das. \& Junior, P. C. S. (2013). Oclusão. 1. ed. São Paulo: Artes Médicas. (Série Abeno - Odontologia Essencial).

Okeson, J. P., \& de Leeuw, R. (2011). Differential diagnosis of temporomandibular disorders and other orofacial pain disorders. Dental clinics of North America, 55(1), 105-120.

Okeson J. P. (2007). Joint intracapsular disorders: diagnostic and nonsurgical management considerations. Dental clinics of North America, 51(1), 85-vi.

Okeson J. P. (2008). The classification of orofacial pains. Oral and maxillofacial surgery clinics of North America, 20(2), 133-v.

Paiva, H. J. D. (2008). Noções e conceitos básicos em oclusão, disfunção temporomandibular e dor orofacial. 1. ed. São Paulo: Santos Editora.

Pantoja, L. L. Q., de Toledo, I. P., Pupo, Y. M., Porporatti, A. L., Canto, G. D. L., Zwir, L. F., \& Guerra, E. N. S. (2019). Prevalence of degenerative joint disease of the temporomandibular joint: a systematic review. Clinical oral investigations, 23(5), 2475-2488.

Peck, C. C., Goulet, J. P., Lobbezoo, F., Schiffman, E. L., Alstergren, P., Anderson, G. C., de Leeuw, R., Jensen, R., Michelotti, A., Ohrbach, R., Petersson, A., \& List, T. (2014). Expanding the taxonomy of the diagnostic criteria for temporomandibular disorders. Journal of oral rehabilitation, 41 (1), 2-23.

Pinto, M. V. D. M., Silva, C. M. D., Gonçalves, R. V., \& Rocha, L. L. V. (2012). Análise dos deslocamentos do disco articular da articulação temporomandibular: revisão de literatura, critérios e exame. Fisioter. Bras, 142-147. 
Poluha, R. L., Canales, G. T., Costa, Y. M., Grossmann, E., Bonjardim, L. R., \& Conti, P. (2019). Temporomandibular joint disc displacement with reduction: a review of mechanisms and clinical presentation. Journal of applied oral science: revista FOB, $27, \mathrm{e} 20180433$.

Rajurkar, S. G., Makwana, R., Ranadive, P., Deshpande, M. D., Nikunj, A., \& Jadhav, D. (2017). Use of Temporalis Fascia Flap in the Treatment of Temporomandibular Joint Ankylosis: A Clinical Audit of 5 Years. Contemporary clinical dentistry, 8(3), 347-351.

Renapurkar S. K. (2018). Discectomy Versus Disc Preservation for Internal Derangement of the Temporomandibular Joint. Oral and maxillofacial surgery clinics of North America, 30(3), 329-333.

Renapurkar S. K. (2018). Surgical Versus Nonsurgical Management of Degenerative Joint Disease. Oral and maxillofacial surgery clinics of North America, 30(3), 291-297.

Roberts, W. E., \& Goodacre, C. J. (2020). The Temporomandibular Joint: A Critical Review of Life-Support Functions, Development, Articular Surfaces, Biomechanics and Degeneration. Journal of prosthodontics: official journal of the American College of Prosthodontists, 29(9), 772-779.

Robin, O. (2015). Éléments de diagnostic des algies de l'appareil manducateur. Douleurs: Evaluation-Diagnostic-Traitement, 16(5), $253-259$.

Rodrigues, R. E., Duarte, P. H. M., \& Feitosa, C. Â. L. (2019). Impacto da osteoartrose de joelho na capacidade funcional e qualidade de vida de pacientes atendidos em um município de Pernambuco, Brasil. Archives Of Health Investigation, 8(7), 361-367.

Schiffman, E., Ohrbach, R., Truelove, E., Look, J., Anderson, G., Goulet, J. P., List, T., Svensson, P., Gonzalez, Y., Lobbezoo, F., Michelotti, A., Brooks, S. L., Ceusters, W., Drangsholt, M., Ettlin, D., Gaul, C., Goldberg, L. J., Haythornthwaite, J. A., Hollender, L., \& Jensen, R.Orofacial Pain Special Interest Group, International Association for the Study of Pain (2014). Diagnostic Criteria for Temporomandibular Disorders (DC/TMD) for Clinical and Research Applications: recommendations of the International RDC/TMD Consortium Network* and Orofacial Pain Special Interest Group $†$. Journal of oral \& facial pain and headache, 28(1), 6-27.

Schiffman, E. L., Velly, A. M., Look, J. O., Hodges, J. S., Swift, J. Q., Decker, K. L., Anderson, Q. N., Templeton, R. B., Lenton, P. A., Kang, W., \& Fricton, J. R. (2014). Effects of four treatment strategies for temporomandibular joint closed lock. International journal of oral and maxillofacial surgery, 43(2), 217226.

Schmidseder, A. R. (2007). Oclusão. (2a. ed.), Santos Editora.

Scrivani, S. J., Keith, D. A., \& Kaban, L. B. (2008). Temporomandibular disorders. The New England journal of medicine, 359(25), $2693-2705$.

Shaffer, S. M., Brismée, J. M., Sizer, P. S., \& Courtney, C. A. (2014). Temporomandibular disorders. Part 1: anatomy and examination/diagnosis. The Journal of manual \& manipulative therapy, 22(1), 2-12.

Sharma R. (2012). Modifications to Norman's procedure for hypermobility of the TMJ. Medical journal, Armed Forces India, 68(3), $231-235$.

Shen, P., Huo, L., Zhang, S. Y., Yang, C., Cai, X. Y., \& Liu, X. M. (2014). Magnetic resonance imaging applied to the diagnosis of perforation of the temporomandibular joint. Journal of cranio-maxillo-facial surgery: official publication of the European Association for Cranio-Maxillo-Facial Surgery, 42(6), 874-878.

Sobral, A. P. T., de Sousa Sobral, S., Giacon, G. G., Campos, T. M., Horliana, A. C. R. T., Fernan des, K. P. S., ... \& Motta, L. J. (2020). Phototherapy versus Occlusal Splint to control painful symptoms in Temporomandibular Disorder: controlled, randomized cost-effectiveness clinical trial. Research, Society and Development, 9(11), e66991110251-e66991110251.

Song, Y. L., \& Yap, A. U. (2018). Outcomes of therapeutic TMD interventions on oral health related quality of life: A qualitative systematic review. Quintessence international (Berlin, Germany: 1985), 49(6), 487-496.

Stocum, D. L., \& Roberts, W. E. (2018). Part I: Development and Physiology of the Temporomandibular Joint. Current osteoporosis reports, 16(4), 360-368.

Sousa, J. D. S. M., do Nascimento Jácome, A., de Resende, C. M. B. M., Barbosa, G. A. S., de Araújo, A. A., \& de Almeida, E. O. (2020). Effectiveness of manual therapy in masticatory muscles for tmd patients-a review of the literature. Research, Society and Development, 9(10), e1319108335-e1319108335.

Takeda, M., Takahashi, M., \& Matsumoto, S. (2012). Suppression of neurokinin-1 receptor in trigeminal ganglia attenuates central sensitization following inflammation. Journal of the peripheral nervous system: JPNS, 17(2), 169-181.

Tamimi, D., Jalali, E., \& Hatcher, D. (2018). Temporomandibular Joint Imaging. Radiologic clinics of North America, 56(1), 157-175.

Tatli, U., Benlidayi, M. E., Ekren, O., \& Salimov, F. (2017). Comparison of the effectiveness of three different treatment me thods for temporomandibular joint disc displacement without reduction. International journal of oral and maxillofacial surgery, 46(5), 603-609.

Tuijt, M., Parsa, A., Koutris, M., Berkhout, E., Koolstra, J. H., \& Lobbezoo, F. (2018). Human jaw joint hypermobility: Diagn osis and biomechanical modelling. Journal of oral rehabilitation, 45(10), 783-789.

Tvrdy P. (2007). Methods of imaging in the diagnosis of temporomandibular joint disorders. Biomedical papers of the Medical Faculty of the University Palacky, Olomouc, Czechoslovakia, 151(1), 133-136.

Valle, R. T.; Grossmann, E.; Fernandes, R. S. M. (2015). Disfunções temporomandibulares: abordagem clínica. $1^{\text {a }}$ edição, São Paulo: Editora Napoleão.

Vapniarsky, N., Huwe, L. W., Arzi, B., Houghton, M. K., Wong, M. E., Wilson, J. W., Hatcher, D. C., Hu, J. C., \& Athanasiou, K. A. (2018). Tissue engineering toward temporomandibular joint disc regeneration. Science translational medicine, 10(446), eaaq1802.

Vilar, E. G. S., Pereira, E. D. S. B. M., Eleutério, R. G., Trazzi, B. F. M., \& da Silva, W. S. (2020). Indicações cirúrgicas de deslocamento do disco articular da articulação temporomandibular. Brazilian Journal of Health Review, 3(5), 13790-13809. 
Research, Society and Development, v. 10, n. 3, e12510313189, 2021

(CC BY 4.0) | ISSN 2525-3409 | DOI: http://dx.doi.org/10.33448/rsd-v10i3.13189

Xu, Y., Zhan, J., Zheng, Y., Han, Y., Zhang, Z., Xi, Y., \& Zhu, P. (2012). Synovial fluid dynamics with small disc perforation in temporomandibular joint. Journal of oral rehabilitation, 39(10), 719-726.

Wang, X. D., Zhang, J. N., Gan, Y. H., \& Zhou, Y. H. (2015). Current understanding of pathogenesis and treatment of TMJ osteo arthritis. Journal of dental research, 94(5), 666-673.

White, T., Hedderick, V., \& Ramponi, D. R. (2016). Dislocation of the Temporomandibular Joint and Relocation Procedures. Advanced emergency nursing journal, 38(3), 177-182.

Young A. L. (2015). Internal derangements of the temporomandibular joint: A review of the anatomy, diagnosis, and management. Journal of Indian Prosthodontic Society, 15(1), 2-7.

Zhang, W., Yang, X., Zhang, Y., Zhao, T., Jia, J., Chang, S., Liu, Y., Yu, B., Chen, Y., \& Ma, Q. (2018). The sequential trea tment of temporomandibular joint ankylosis with secondary deformities by distraction osteogenesis and arthroplasty or TMJ reconstruction. International journal of oral and maxillofacial surgery, 47(8), 1052-1059.

Zotti, F., Albanese, M., Rodella, L. F., \& Nocini, P. F. (2019). Platelet-Rich Plasma in Treatment of Temporomandibular Joint Dysfunctions: Narrative Review. International journal of molecular sciences, 20(2), 277. 